\title{
Quantification of uncertainty associated with injecting carbon dioxide, and design of ECBM reservoir in Appalachian basin coals
}

Jesma Mohan

West Virginia University

Follow this and additional works at: https://researchrepository.wvu.edu/etd

\section{Recommended Citation}

Mohan, Jesma, "Quantification of uncertainty associated with injecting carbon dioxide, and design of ECBM reservoir in Appalachian basin coals" (2010). Graduate Theses, Dissertations, and Problem Reports. 2175.

https://researchrepository.wvu.edu/etd/2175

This Thesis is protected by copyright and/or related rights. It has been brought to you by the The Research Repository @ WVU with permission from the rights-holder(s). You are free to use this Thesis in any way that is permitted by the copyright and related rights legislation that applies to your use. For other uses you must obtain permission from the rights-holder(s) directly, unless additional rights are indicated by a Creative Commons license in the record and/ or on the work itself. This Thesis has been accepted for inclusion in WVU Graduate Theses, Dissertations, and Problem Reports collection by an authorized administrator of The Research Repository @ WVU. For more information, please contact researchrepository@mail.wvu.edu. 


\title{
QUANTIFICATION OF UNCERTAINTY ASSOCIATED WITH INJECTING CARBON DIOXIDE, AND DESIGN OF ECBM RESERVOIR IN APPALACHIAN BASIN COALS
}

\author{
Jesma Mohan \\ Thesis Submitted to the \\ College of Engineering and Mineral Resources \\ at West Virginia University \\ in partial fulfillment of the requirements \\ for the degree of \\ Master of Science \\ In \\ Petroleum and Natural Gas Engineering
}

Yueming Cheng, Ph.D, Chair

Kashy Aminian, Ph.D

Samuel Ameri, M.S

Morgantown, West Virginia

2010

Keywords: Petroleum and Natural Gas Engineering, Coal bed Methane, Simulation, Carbon dioxide Injection, Probabilistic Analysis, Appalachian Basin 


\title{
ABSTRACT \\ QUANTIFICATION OF UNCERTAINTY ASSOCIATED WITH INJECTING \\ CARBON DIOXIDE, AND DESIGN OF ECBM RESERVOIR \\ IN APPALACHIAN BASIN COALS
}

\author{
Jesma Mohan \\ Chair of Advisory Committee: Dr. Yueming Cheng
}

There are tremendous coal bed methane resources throughout the world. However, with conventional production methods, $40-80 \%$ of methane is left behind as unrecoverable. Enhanced coal bed methane (ECBM) recovery by injection of Carbon dioxide (CO2) is motivated by the dual benefits of improved gas recovery and green house gas storage. In practice, this technology is relatively new, still in the early stage of development, and the economic performance of ECBM has yet to be verified. Due to the complexity of CBM reservoirs, the production performance involves significant uncertainties. It is imperative to quantify the uncertainty of production performance in order to improve the economics of ECBM.

Uncertainty of production performance can be analyzed by reservoir modeling coupled with stochastic method such as Monte Carlo Simulation. This procedure has been proven to be an effective methodology to predict production profiles with a wide variety of reservoir properties and producing conditions. In this study, a commercial reservoir simulator is coupled with Monte Carlo simulation. Rapid assessment of CO2- ECBM performance uncertainties can be realized by considering probabilistic distributions of coal bed properties, such as cleat spacing, permeability anisotropy, water saturation, porosity and isotherm parameters like Langmuir pressure and Langmuir Volume. CO2-ECBM design, such as well pattern, well spacing and $\mathrm{CO} 2$ injection rate, can be investigated under these uncertain coal bed properties.

The approach is illustrated using an example case from Appalachian Basin Coals, and provides a new insight on understanding the impacts of uncertain factors on production performance as well as optimization of CO2-ECBM design. 


\section{DEDICATION}

This work is dedicated to:

My parents, for their unlimited love and support all through my life;

My brother, sister and my aunt for their encouragement;

And my beloved Husband. 


\section{ACKNOWLEDGEMENT}

This research was conducted at West Virginia University under the supervision of Dr. Yueming Cheng. I would like to express my sincere thanks to Dr. Cheng, for her technical advice and consistent support in pursuing this study. In particular, I am grateful for her patience during several lengthy discussions, despite her tight schedule; she always made herself available whenever I needed any assistant. My gratitude also goes to the other members of my committee, Dr. Kashy Aminian and Professor Samuel Ameri. I would like to express heartfelt thanks to Professor Samuel Ameri, Chair of the petroleum and Natural Gas Department at West Virginia University, for the financial and moral support all through my Masters program.

I highly appreciate the encouragement from my parents and my husband. I would also like to thank Mr. Karthik Narayanan for guiding me with Visual Basic Application and helping me meet the programming demands of the project.

My thanks also goes to all the members of the Petroleum and Natural Gas Department, Ms. Beverly Matheny, and my friends who have helped me keep up my spirit. Above all, I give special gratitude to Almighty God for giving me the opportunity to undertake and complete this study. 


\section{Contents}



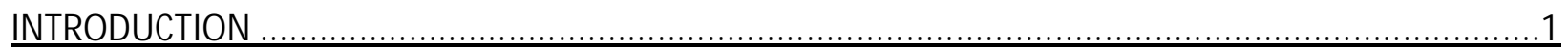

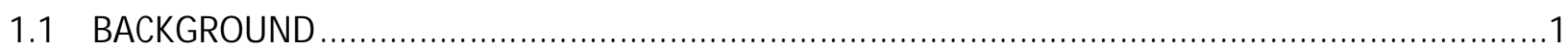

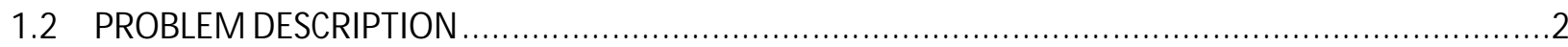

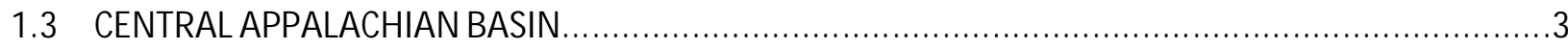

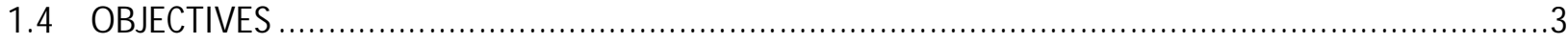

1.5 ORGANISATION OF THE THESIS..................................................................................

CHAPTER 2

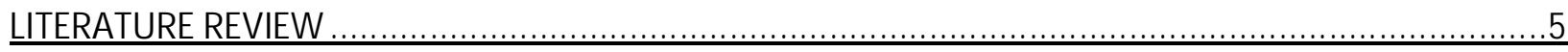

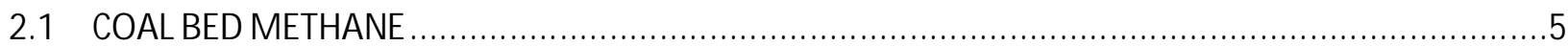

2.1 GREEN HOUSE GAS EM ISSION AND GLOBAL WARM ING ...................................................8

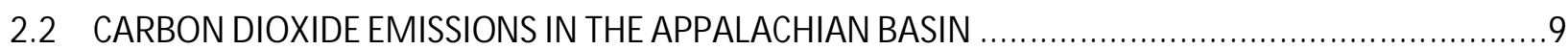

2.3 GREEN HOUSE GAS SEQUESTRATION ................................................................................10



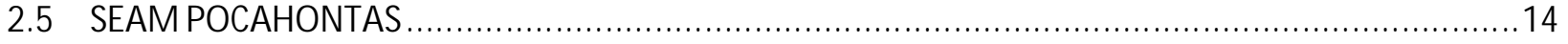

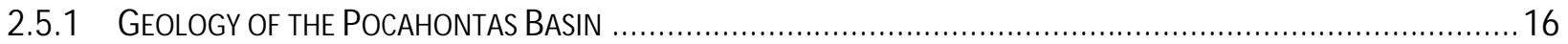

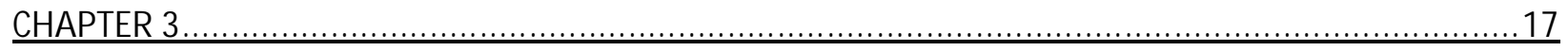

METHODOLOGY

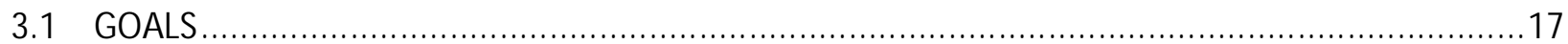

3.2 METHODOLOGY .........................................................................................................17

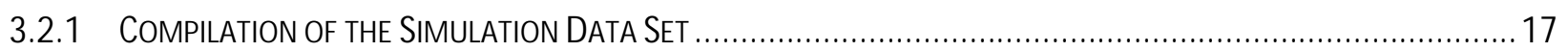

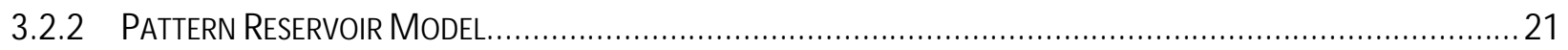

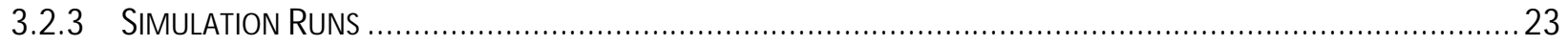

CHAPTER 4

RESULT AND DISCUSSION 
4.1 RESERVOIR SIM ULATION STUDIES ........................................................................26

4.1.1 CO2 SEQUESTRATION/ ECBM PRODUCTION BASE CASE SCENARIOS - CASE (1A ) FOR 5-SPOT PATTERN ............26

4.1.1.1 Cumulative $\mathrm{CO} 2$ injection Statistics for base case (1a) ...................................................29

4.1.1.2 Cumulative $\mathrm{CH}_{4}$ production Statistics for base case (1a) ....................................................30

4.1.1.3 Statistical Analysis of Breakthrough time for base case (1a) ................................................. 31

4.1.2 CO2 SEQUESTRATION/ ECBM PRODUCTION BASE CASE (1B): INVERTED 7-SPOT PATTERN ............................. 31

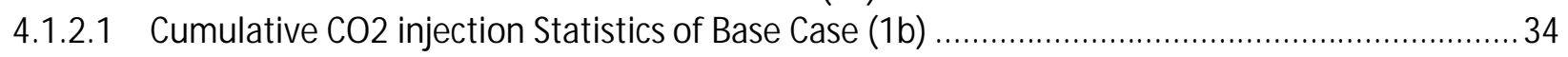

4.1.2.2 Cumulative $\mathrm{CH} 4$ production Statistics for Base Case (1b) ............................................... 35

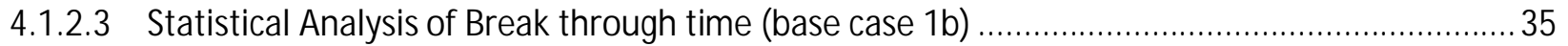

4.1.3 SENSITIVITY STUDY OF THE EFFECTS OF WELL SPACING (INVERTED 5 SPOT PATTERN) ................................... 36

4.1.4 SENSITIVITY STUDY OF THE EFFECT OF CO2 INJECTION RATE (INVERTED 5 SPOT PATTERN) ............................. 42

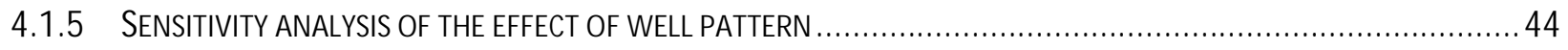

CHAPTER 5

CONCLUSION AND RECOM MENDATION

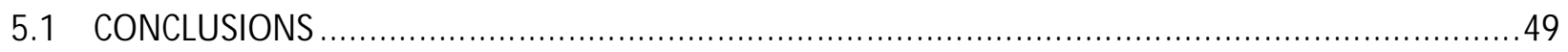

5.2 RECOM MENDATIONS ..............................................................................................50

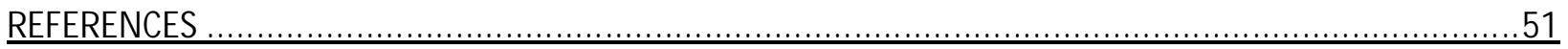




\section{LIST OF FIGURES}

FIGURE 1.1: FLOWCHART TO SHOW THE VARIOUS UNCERTAINTY SOURCES CONSIDERED IN THIS STUDY. ..........................................2

FIGURE 2.1: THE RELATIONSHIP BETWEEN PARTIAL PRESSURE AND THE GAS ADSORBED TO A UNIT M ASS OF COAL IS DESCRIBED BY THE

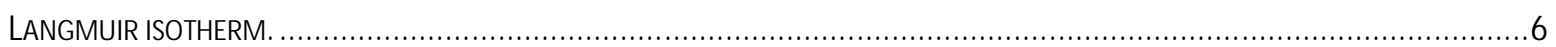

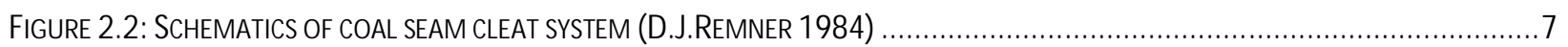

FIGURE 2.3: SCHEM ATICS OF M ETHANE FLOW DYNAMICS IN COAL SEAM S (D.J.REM NER 1984) ...............................................

FIGURE 2.4: ILLUSTRATION OF THE FUTURE TRENDS IN GLOBAL WARM ING (EM ISSIONCREDITS 2009) ..........................................



FIGURE 2.6: M AP SHOWING THE LOCATION OF NORTHERN, CENTRAL AND SOUTHERN COAL REGIONS IN THE APPALACHIAN BASIN. THE SEAM POCAHONTAS No.3 COAL BEDS OCCUR IN THE CENTRALAPPALACHIAN BASIN.................................................. 15

FIGURE 2.7: M AP SHOWING THE AREAL EXTENT OF THE POCAHONTAS NO.3 COAL BED, WHICH EXTENDS THROUGH 12 COUNTIES IN

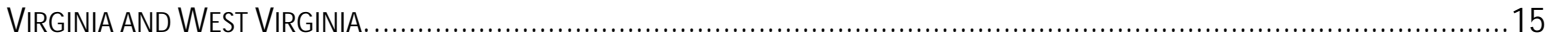

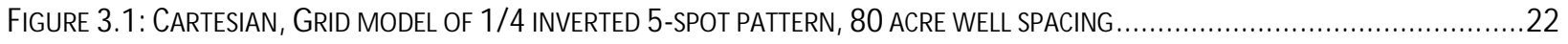

FIGURE 3.2: CARTESIAN GRID M ODEL OF 1/12 INVERTED 7-SPOT PATTERN, 80 ACRE WELL SPACING.......................................22

FIGURE 3.3: GRID SENSITIVITY COM PARISON RESULTS FOR CUMULATIVE CO2 INJECTION AND CH4 PRODUCTION PROFILES, TWO GRID SIZES

23

FIGURE 3.4: FLOWCHART SHOWING THE PROCEDURES OF THE COM PUTER PROGRAM DESIGN ….............................................24

FIGURE 4.1: A) CARBON DIOXIDE GAS M OLE FRACTION, B) M ETHANE GAS M OLE FRACTION C) RESERVOIR PRESSURE AT BREAK POINT, AND D) WATER SATURATION IN THE FRACTURE SYSTEM FOR ONE OF THE SAM PLES IN THE BASE CASE(1A) SCENARIO OF INVERTED 5 SPOT

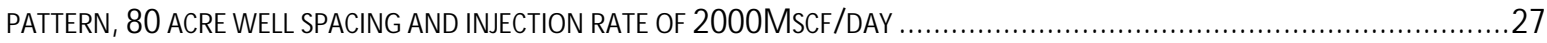

FIGURE 4.2A: M ETHANE PRODUCTION RATE, W ATER PRODUCTION RATE AND WELL BOTTOM HOLE PRESSURE FOR THE PRODUCTION WELL

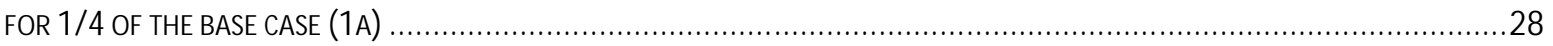

FIGURE 4.2B: INJECTION WELL BOTTOM HOLE PRESSURE FOR 1/4TH BASE CASE SCENARIO(1A) ................................................2

FIGURE 4.3: A) M ETHANE GAS M OLE FRACTION, B) CARBON DIOXIDE GAS M OLE FRACTION, C) WATER SATURATION IN THE FRACTURE SYSTEM , AND D) RESERVOIR PRESSURE AT BREAK POINT FOR ONE OF THE SAM PLES IN THE BASE CASE(1B) OF INVERTED 7 SPOT PATTERN, 80 ACRE WELL SPACING AND INJECTION RATE OF 2000M SCF/DAY ........................................................... 32

FIGURE 4.4A: M ETHANE PRODUCTION RATE AND W ATER PRODUCTION RATE FOR 1/ 12 OF INVERTED 7-SPOT PATTERN BASE CASE (1B).. 33

FIGURE 4.4B: INJECTION WELL BOTTOM HOLE PRESSURE FOR 1/12 OF INVERTED 7-SPOT PATTERN BASE CASE (1B). .........................33

FiguRE 4.5: CUM ULATIVE DISTRIBUTION FUNCTION GRAPHS FOR (A) CUM ULATIVE CO2 INJECTION TOTAL, (B) CUMMULATIVE CH4 PRODUCTION TOTAL, (C) BREAKTHROUGH TIME FOR AN INVERTED 5-SPOT PATTERN AND CONSTANT CO2 INJECTION RATE OF 1000

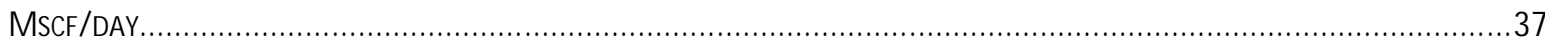

FiguRE 4.6: CUMULATIVE DISTRIBUTION FUNCTION GRAPHS FOR (A) CUM ULATIVE CO2 INJECTION TOTAL, (B) CUM ULATIVE CH4 PRODUCTION TOTAL, (C) BREAKTHROUGH TIM E FOR AN INVERTED 5 SPOT PATTERN AND CONSTANT CO2 INJECTION RATE OF 2000

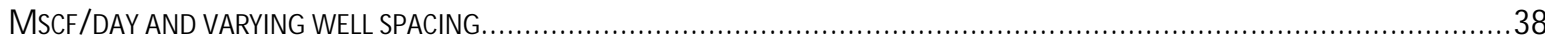

FIGURE 4.7: CUM ULATIVE DISTRIBUTION FUNCTION GRAPHS FOR (I) CUMULATIVE CO2 INJECTION TOTAL, (II) CUMULATIVE CH4 PRODUCTION TOTAL, (III) BREAKTHROUGH TIME FOR AN INVERTED 5 SPOT PATTERN AND CONSTANT CO2 INJECTION RATE OF 3000

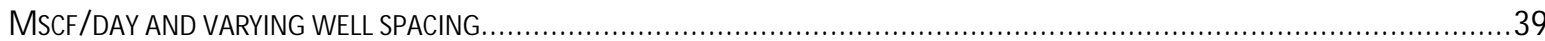

FIGURE 4.8: CUM ULATIVE DISTRIBUTION FUNCTION GRAPHS FOR (I) CUMULATIVE CO2 INJECTION TOTAL, (II) CUMULATIVE CH4 PRODUCTION TOTAL, (III) BREAKTHROUGH TIME FOR AN INVERTED 5 SPOT PATTERN AND CONSTANT CO2 INJECTION RATE OF 4000



FIGURE 4.9: CUM ULATIVE DISTRIBUTION FUNCTIONS FOR A) CO2 INJECTION, B) CH4 PRODUCTION........................................ 41 INVERTED 5-SPOT PATTERN SCENARIO, FOR 40, 80, 160, AND 240-AC WELL SPACING, NORM ALIZED TO A 40-ACRE WELL SPACING (80-

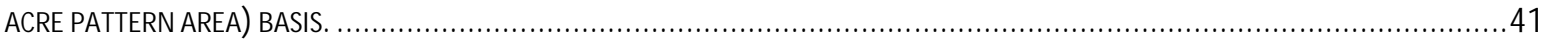

FIGURE 4.10: M EAN VALUES FOR CUM ULATIVE CO2 INJECTION TOTAL AT VARIOUS INJECTION RATES. ........................................42

FIGURE 4.11: CUM ULATIVE CH4 PRODUCTION TOTALAS A FUNCTION OF CO2 INJECTION RATE. ..............................................43

FIGURE 4.12: M EAN PRODUCTION TIME AS A FUNCTION OF CO2 INJECTION RATE.......................................................... 44 
FiguRE 4.13: CUM ULATIVE DISTRIBUTION FUnCTION GRAPHS FOR (A) CUMULATIVE CO2 INJECTION TOTAL, (B) CUMULATIVE CH4 PRODUCTION TOTAL AND C) BREAKTHROUGH TIME FOR FIXED 1000 M SCF/DAY CO2 INJECTION RATE AND FIXED 80 ACRE WELL SPACING WHILE VARYING WELL PATTERN (INVERTED 5 SPOT AND INVERTED 7 SPOT).

FIGURE 4.14: CUM ULATIVE DISTRIBUTION FUNCTION GRAPHS FOR (A) CUMULATIVE CO2 INJECTION TOTAL, (B) CUM ULATIVE CH4 PRODUCTION TOTAL, FOR FIXED 2000 M SCF/ DAY CO2 INJECTION RATE AND FIXED 80 ACRE WELL SPACING WHILE VARYING WELL PATTERN (INVERTED 5 SPOT AND INVERTED 7 SPOT).

FIGURE 4.15: THE CUMULATIVE CO2 INJECTION TOTAL FOR INVERTED 5-SPOT AND INVERTED 7-SPOT PATTERN WHILE THE WELL SPACING

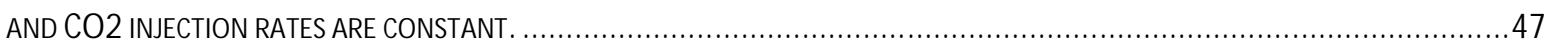

FIGURE 4.16: CUMULATIVE M ETHANE PRODUCTION FOR INVERTED 5-SPOT AND INVERTED 7-SPOT PATTERN ..................................47

FIGURE 4.17: CUM ULATIVE M ETHANE PRODUCTION TOTAL FOR INVERTED 5-SPOT AND INVERTED 7-SPOT PATTERNS ..........................48

FIGURE 4.18: M ETHANE PRODUCTION RATE FOR INVERTED 5-SPOT AND INVERTED 7-SPOT PATTERNS .........................................48 


\section{LIST OF TABLES}

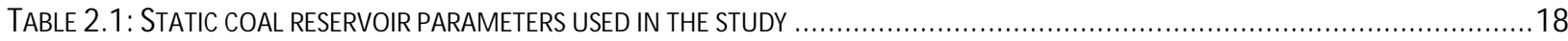

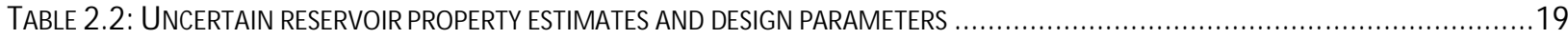

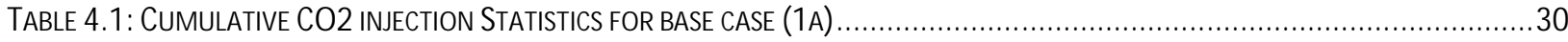

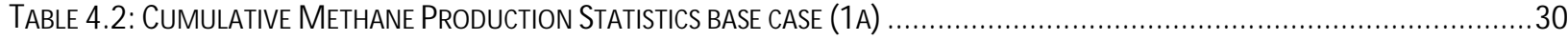

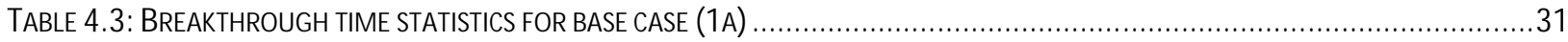

TABLE 4.4: CUM ULATIVE CO2 INJECTION STATISTICS FOR INVERTED 7-SPOT PATTERN WITH 80 ACRE WELL SPACING AND 2000 M SCF/ DAY

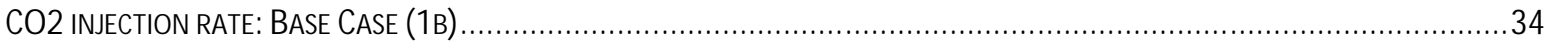

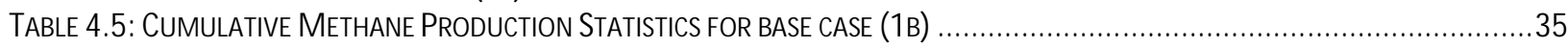

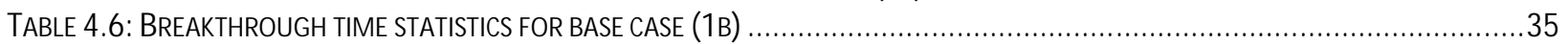




\section{CHAPTER 1}

\section{INTRODUCTION}

\subsection{BACKGROUND}

Over the last 15 years, Coal bed Methane has become a well-established part of the domestic gas industry. Currently, about 10 percent of the total natural gas production in the United States comes from coal bed methane wells. The total Coal Bed Methane gas in place in the U.S Coal beds is estimated to be $400 \mathrm{TCF}$, of which about $95 \mathrm{TCF}$ is believed to be economically recoverable using the current reservoir pressure depletion technology. This proves that there is a significant resource left unexploited. And, there is a need for alternative methods of unconventional gas recovery. (Yee.D 1990)

Injecting Carbon dioxide into the Coal bed methane reservoir has been proven to significantly enhance the production of Methane because CO2 sorbs more strongly to coal than methane does. Various literature have been established on how, this method also facilitates underground storage of Carbon dioxide, a greenhouse gas believed to cause global warming and other undesirable environmental issues like acid rain, deforestation etc. Thus, this method of Enhanced Coal bed methane recovery by injecting Carbon dioxide presents a dual benefit of improved coal bed methane recovery and sequestration of $\mathrm{CO} 2$ at the same time.

Due to the heterogeneity of the Coal Bed Methane reservoirs, the productivity depends on a set of inter-related reservoir, completion and production properties. Injecting Carbon dioxide into the reservoir leads to too many parameters influencing the production profiles, thus resulting in higher degree of risk and uncertainty. However, there is a strong need to understand the risks and uncertainties associated with Enhanced Coal bed Methane recovery, in order to commercialize the process. (Reinaldo J. Gonzalez 2006) 


\subsection{PROBLEM DESCRIPTION}

The purpose of this study is to use stochastic methods and to predict the uncertainty of production performances using an example case from Central Appalachian basin coals.

Uncertainty associated with various operating scenarios like different well patterns, well spacing and Carbon Dioxide injection rates are to be investigated under a range of coal bed methane reservoir properties.

The overall flowchart of the various uncertainty sources associated with injecting Carbon Dioxide considered in this study is illustrated in figure 1.

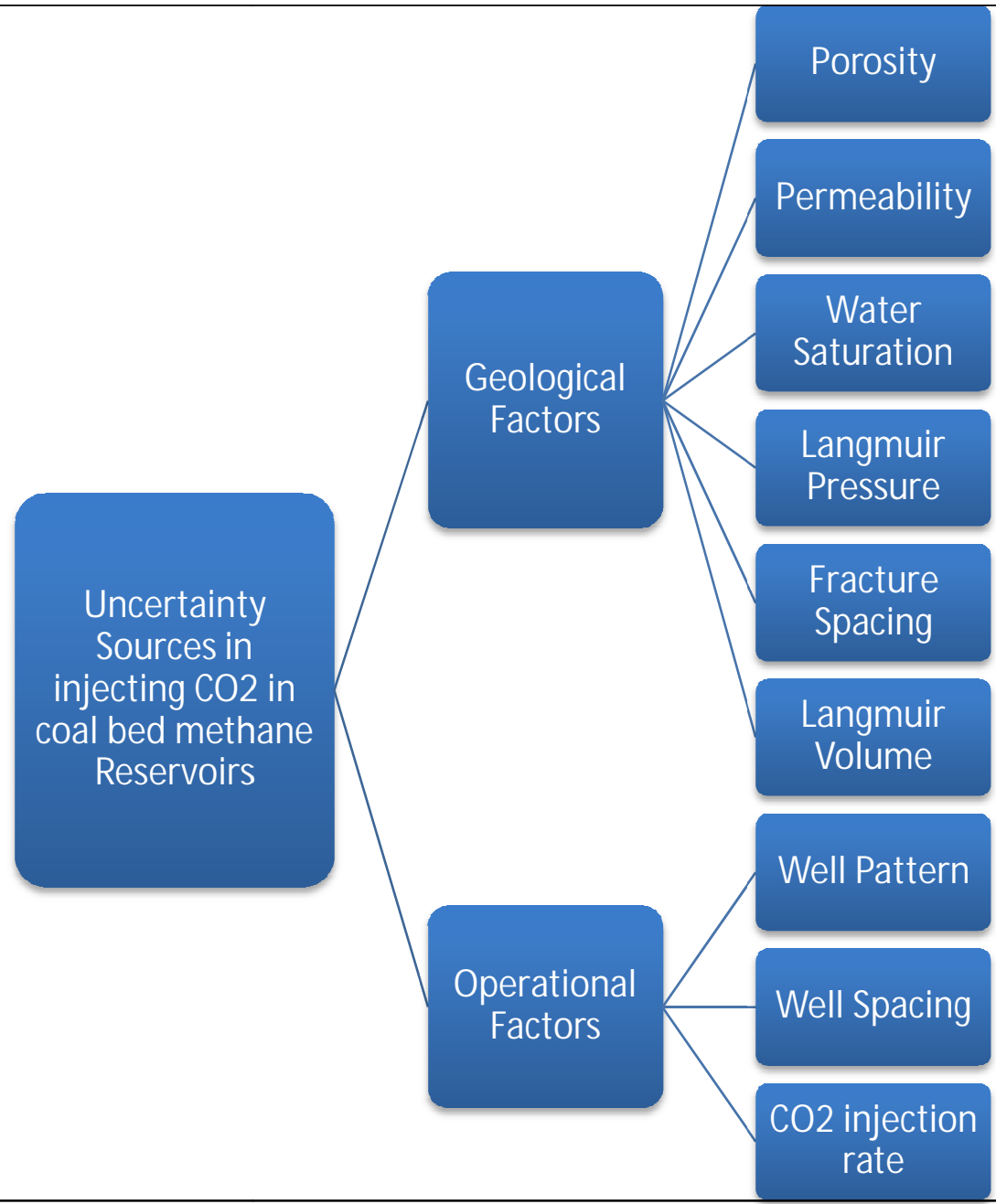

Figure 1.1: Flowchart to show the various uncertainty sources considered in this study. 


\subsection{CENTRAL APPALACHIAN BASIN}

The Appalachian Basin in the Eastern United States has some of the major coal bed methane plays such as Dunkard, Pocahontas and Warrior Basin. While Coal bed Methane development may be regarded as mature in the Southern Appalachian Basin where production in Alabama is relatively constant at about 110 Billion Cubic feet annually, there is still opportunity for growth in the Central and Northern Appalachian basin. It is a known fact that most of the coal beds of the Appalachian basin in West Virginia, Virginia and Pennsylvania are mineable. This research is not directed towards such coal fields; instead it aims at exploiting the Coal bed methane wells in the deep unmineable coal fields of the Appalachian basin. There are about 5113 active coal bed methane wells in the Appalachian basin producing about 1.5 trillion cubic feet of methane annually. Most of these wells are aimed at the deep unmineable coal beds and conventional methods are being used for methane production. This poses an opportunity for further exploitation by injecting carbon dioxide. (C.Milici n.d.)

The data in this study was carefully selected to imitate the deep and unmineable coal fields of the Central Appalachian basin such as the Seam Pocahontas which have depth range from 1050 to $2500 \mathrm{ft}$. (C.Milici n.d.)

\subsection{OBJECTIVES}

The overall goal of this research is to predict the uncertainties associated with injecting Carbon dioxide into the central Appalachian Basin. Therefore, numerical modeling was done to address the following doubts:

- Determine the potential for enhanced methane recovery from the Central Appalachian Basin coals as an added benefit of $\mathrm{CO} 2$ sequestration.

- Evaluate the effect of well spacing, injection rate and Well pattern on the CO2 injection and methane production rates.

- Determine the optimum values for well spacing, injection rate of CO2 and well pattern for the maximum $\mathrm{CO} 2$ sequestration and methane production. 
- Quantify uncertainty in potential CO2 sequestration in, and methane production from, the coalfields of Central Appalachian Basin.

To achieve these objectives, numerical reservoir models were required to simulate injection and production of carbon dioxide and methane respectively.

A reservoir simulation was conducted for combination of most important reservoir parameters. It was then coupled with Monte Carlo simulation to conduct probabilistic reservoir simulation modeling studies consisting of thousands of simulation runs. Several cases were analyzed by simulating different operating conditions and scenarios. This amounted to many more thousands of runs. Analysis of this data allowed in quantifying the uncertainties in my forecasts of $\mathrm{CO} 2$ sequestration and methane production.

\subsection{ORGANISATION OF THE THESIS}

The outline of this thesis is as follows:

The first chapter of the thesis report starts with Introduction, which elaborates the background, Problem statement, Objective of the Study and, the Organization of the Thesis.

Chapter 2 presents a comprehensive literature review related to the various technologies of coal bed methane, injection of Carbon Dioxide as well as modeling and simulation developed and presented by various authors. The various literature used in this study have been elaborated in this section.

Chapter 3 discusses the Methodology applied in the study. The coal bed methane data set is tabulated and the various processes used in order to derive the conclusion are presented step by step. A detailed discussion of the Numerical Simulations performed in this project is presented in Chapter 3, which is the Reservoir Modeling section. In this section, first the selection of the reservoir simulator and compilation of the coal bed simulation data set is elaborated. After explaining the basic model and the operational parameters, the results of the simulation runs and the sensitivity of these results to reservoir and operational parameters are illustrated.

Finally, in chapter 4, the results are discussed and in chapter 5, conclusions are drawn regarding the need for additional investigation, the effect of $\mathrm{CO} 2$ injection rate, well pattern and well spacing on the ECBM production and Carbon dioxide sequestration. 


\section{CHAPTER 2}

\section{LITERATURE REVIEW}

\subsection{COAL BED METHANE}

Coal gas reservoirs are dual storage reservoirs which consist of both primary and secondary storage systems. The primary storage systems usually makes up to $98 \%$ or higher of the reservoir volume and contains organic matter, inorganic material, inherent water, and gas stored within very small pore spaces. Primary system gas storage is dominated by sorption phenomena because of the small size of the pores. During sorption, the molecules are within very close proximity to solid surfaces, are attracted to the solid, and are packed closer together than expected from the pressure conditions. The primary porosity system is relatively impermeable and mass transfer is dominated by diffusion i.e., driven by gas concentration gradient. Commercially productive coal gas reservoirs contain a well-developed secondary storage system dominated by natural fractures. Without natural fractures, commercial production will not be possible. Flow through the secondary storage system is due to pressure gradients between the fracture system and production wells. The majority of gas in a coal gas reservoir diffuses through the primary storage system, desorbs at the interface between the primary and secondary systems and then flows through the secondary system to wells. (Mathew J.Mavor 2002)

The pressure-adsorption relationship is modeled for the constant temperature environment found in coal seams using the Langmuir isotherm (Figure. 1). Normally methane is the only gas present in the coal reservoir, so the partial pressure for methane is essentially equal to the reservoir pressure. The reservoir pressure is reduced by producing the water in the formation. As the pressure decreases, the methane desorbs from the coal surface and flows through fractures (cleats) to the wellbore. 


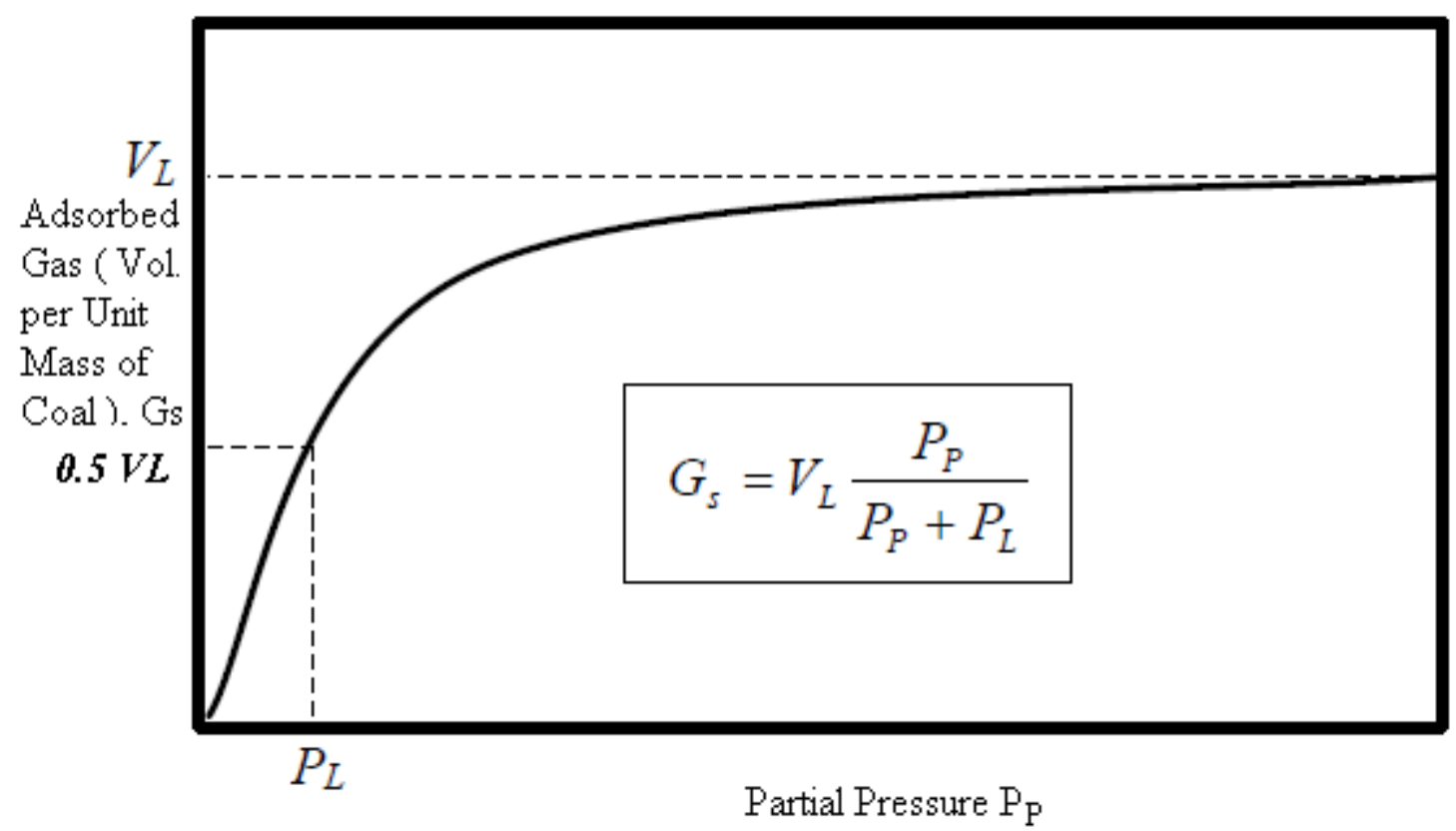

Figure 2.1: The relationship between partial pressure and the gas adsorbed to a unit mass of coal is described by the Langmuir isotherm.

However, this current technology used to produce methane from the Coal bed methane reservoirs has low recovery percentage. The conventional method of methane recovery by depleting the reservoir pressure is simple and effective but it is not efficient. Loss in the pressure deprives the reservoir fluids' energy necessary to flow to the well bore. Consequently, gas production rates reduce and the ultimate methane recovery by this technique is not expected to be more than $50 \%$ of the total gas in place even after decades of production.

It is believed that injecting gases like $\mathrm{CO} 2$ and $\mathrm{N} 2$ into the coal bed methane reservoirs produce a way for higher recovery percentage. The $\mathrm{CO} 2$ sequestration/enhance coal bed methane process works by replacing adsorbed methane molecules in the primary storage system with adsorbed $\mathrm{CO} 2$ molecules. The $\mathrm{CH} 4$ molecules are displaced into the coal natural fracture system and there is little breakthrough to production wells until the majority of the well pattern is swept. A sequestration project terminates at $\mathrm{CO} 2$ breakthrough of 5\%. At this breakthrough point, in an ideal case $70 \%$ of the reservoir is swept. (Mathew J.Mavor 2002) 


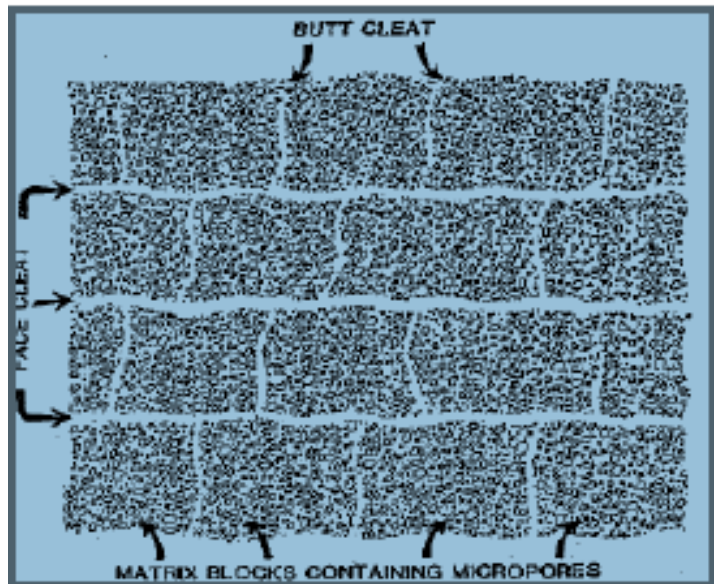

Figure 2.2: Schematics of coal seam cleat system (D.J.Remner 1984)

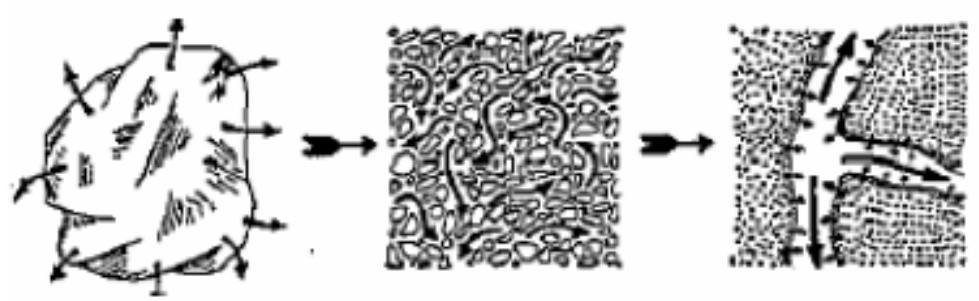

Figure 2.3: Schematics of methane flow dynamics in coal seams (D.J.Remner 1984)

Olufemi Odusote et al in the SPE paper 90055 conducted a parametric study on the various parameters affecting the coal bed methane production. The effects of coal seam properties like porosity, permeability, fracture spacing, $\mathrm{CH} 4$ sorption volume constant (Langmuir), $\mathrm{CH} 4$ Sorption pressure constant (Langmuir), CO2 sorption Volume Constant (Langmuir), CO2 sorption Pressure constant (Langmuir), Initial reservoir pressure, Initial water saturation, Initial Free Gas composition were studied. His study concluded that the $\mathrm{CO} 2$ injected into the coal seam during sequestration is effective in stripping the initially adsorbed methane within the swept area while staying adsorbed on the coal surface. Larger volumes of $\mathrm{CO} 2$ could be injected into coal seams that had lower permeabilities, smaller cleat/fracture spacing. (Olufemi Odusote 2004) 


\subsection{GREEN HOUSE GAS EMISSION AND GLOBAL WARMING}

Green house gas emission accounts for major environmental problems in the United States and around the world. The gradual warming of the earth's surface due to increased entrapment of solar radiation in the atmosphere is known as the greenhouse effect. The most important green house gases $(\mathrm{GHG})$ that contribute to this effect are water vapor $\left(\mathrm{H}_{2} \mathrm{O}\right)$, carbon dioxide $\left(\mathrm{CO}_{2}\right)$, methane $\left(\mathrm{CH}_{4}\right)$, nitrous oxide $\left(\mathrm{N}_{2} \mathrm{O}\right)$, tropospheric ozone $\left(\mathrm{O}_{3}\right)$, and man- made chlorofluorocarbons, with $\mathrm{CO}_{2}$ accounting for $63.6 \%$ of the relative contribution.

Carbon dioxide is produced whenever a carbon-based fuel is burnt (combustion). This can be illustrated by the Methane combustion equation illustrated below:

$$
\mathrm{CH}_{4}+2 \mathrm{O}_{2} \rightarrow \mathrm{CO}_{2}+2 \mathrm{H}_{2} \mathrm{O}+\text { Heat }
$$

The primary $\mathrm{CO}_{2}$ source is emissions from coal combustion for electricity generation, which is the largest source of energy from the earth. Carbon dioxide, one of the most abundant green house gas, when emitted into the environment result in a number of problems including Global warming, Acid rain, Deforestation etc. These emissions are mostly from industries and electric power sectors, which is inevitable.

Increasing concentrations of greenhouse gases in the atmosphere may be leading to changes in the Earth's Climate. Since the 1950's, it has been suspected that small increases in green house gases have resulted in the increase in mean annual surface temperature of the earth, which is about $15^{\circ} \mathrm{C}$. Scientists estimate that an increase of $0.25^{\circ} \mathrm{C}$ has resulted between 1880 and 1940. While the increase in the average temperature does not seem significant, the temperature increase in desert and frozen regions is believed to be much greater and may have a profound effect upon vegetation and sea levels in the future. Many countries have pledged to reduce the emissions of greenhouse gases up to $8 \%$ relative to the levels pertaining in the 1990's. SPE 84423, (Mathew J.Mavor 2002)

Figure 2.4 illustrates Climate changes characterized as global warming, leading to large-scale irreversible effects at continental and global scales. The likelihood and magnitude of the effects are observed and predicted to be increasing and accelerating. 


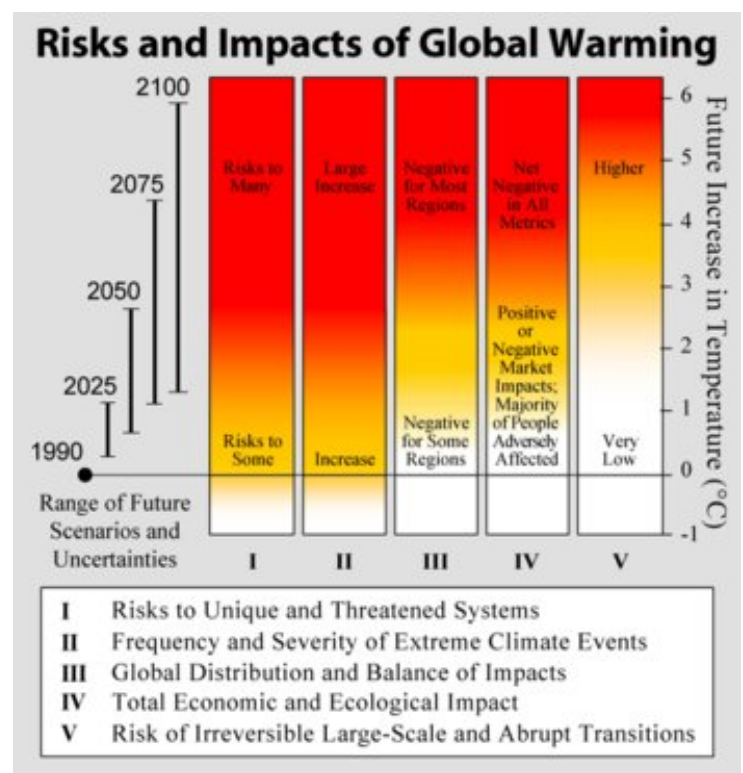

Figure 2.4: Illustration of the future trends in global warming (EmissionCredits 2009)

\subsection{CARBON DIOXIDE EMISSIONS IN THE APPALACHIAN BASIN}

The United States is the world's largest single emitter of carbon dioxide, accounting for 23 percent of energy-related carbon emissions worldwide. Carbon emissions in North America reached 1,760 million metric tons in 1998, a 38 percent increase since 1970. They are expected to grow another 31 percent, to 2,314 million metric tons, by the year 2020. (U.S Department of Energy, 2004). Carbon dioxide $\left(\mathrm{CO}_{2}\right)$ emissions have increased with industrialization in the last century. Coal-fired power plants are among the largest point sources of $\mathrm{CO}_{2}$ emissions.

According to the information provided by the Energy Information Administration, the states with highest $\mathrm{CO} 2$ emissions are Texas, Florida, Pennsylvania, Indiana and Ohio. Texas emits as much as 224.76 million metric tons, which is the highest of all the states in North America.

(Figure 1) The state of Florida emits 127.21 million metric tons. The states of Pennsylvania, Indiana and Ohio emit 119.52, 124.44, 120.05 million metric tons of $\mathrm{CO} 2$ respectively.

It is clearly evident that, the northeast states of Pennsylvania, Indiana and Ohio together are the responsible for millions of tons of $\mathrm{CO} 2$ emitted and can be used as a source for $\mathrm{CO} 2$ sequestration in the Appalachian Basin coal beds. 


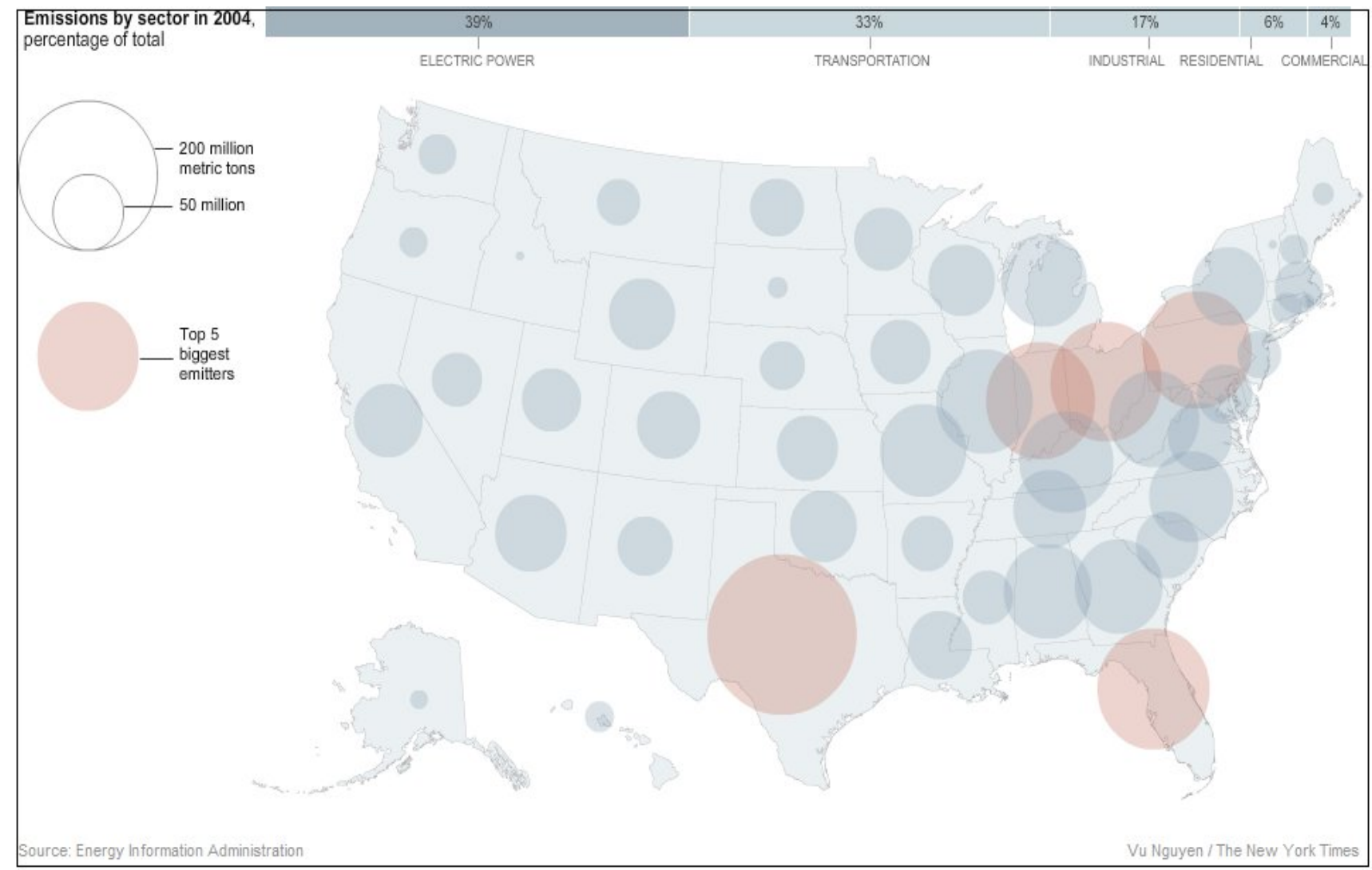

Figure 2.5: Emission of Carbon dioxide by sector in 2004

\subsection{GREEN HOUSE GAS SEQUESTRATION}

Reducing the total $\mathrm{CO} 2$ emissions into the atmosphere in order to control the overall levels of $\mathrm{CO} 2$ in the atmosphere has become an international priority in the wake of the Kyoto protocol. Despite all past and ongoing efforts put into the development of sustainable energy supply, the world still heavily depends on fossil fuels and will continue to do so for years to come. For this reason, technology options are required that will allow for the continued use of fossil fuels without substantial emissions of $\mathrm{CO} 2$. Subsurface storage of $\mathrm{CO} 2$ into geological systems is considered as one promising perspective, which is currently being investigated worldwide. In general, the research window for projects on subsurface $\mathrm{CO} 2$ storage has slowly and steadily shifted from desk studies to demonstrations. (H.J.M. Pagnier 2005)

There are several options for sequestering $\mathrm{CO}_{2}$ that is vented into the atmosphere. These options are broadly grouped into three categories: 
- Biosphere Sinks, which is defined as natural incorporation of CO2 into oceans and forests,

- Geosphere Sinks, where CO2 is injected into natural reservoirs, and

- Material Sinks, which is the use of $\mathrm{CO}_{2}$ in wood products, chemicals, or plastics.

$\mathrm{CO}_{2}$ injection into Coal bed Methane reservoirs belongs to the category of geosphere sinks, in which the greenhouse gas is sequestered in the Coal beds which is the earth. One distinctive benefit of geosphere sinks is the possibility of using injected $\mathrm{CO}_{2}$ to increase hydrocarbon recovery, thereby reducing operational costs. This study is to perform probabilistic analysis on the uncertainties involved in injecting Carbon dioxide into Coal Beds of Central Appalachian Basin.

\subsection{ENHANCED COAL BED METHANE RECOVERY (ECBM)}

In the last few years several pilot projects in Colorado, New Mexico and Alabama have shown the viability of injecting gases such as $\mathrm{CO}_{2}$ and $\mathrm{N}_{2}$ into coal bed methane reservoirs as a method of production enhancement. Coal is known to preferentially adsorb $\mathrm{CO}_{2}$ over methane and to adsorb several times more volumes of $\mathrm{CO}_{2}$ than methane. Thus, when $\mathrm{CO}_{2}$ is injected into a coal seam it displaces the methane from the coal surface. Thereafter, methane desorbs from the coal and flows into the production wells.

In general, the conventional coal bed methane production process and the injection of $\mathrm{CO} 2$, includes the following steps: 1) depressurization of the reservoir by removing in-place water, 2) methane desorption from the bulk matrix and diffusing through it to the fracture network, 3) methane flow into the fracture network under the influence of pressure gradients, 4) $\mathrm{CO} 2$ injection, increase in pressure gradients, and drive of methane production, 5) displacement of methane on the coal surfaces by $\mathrm{CO} 2$ injection with decrease on the methane partial pressure in the gas mixture. (D. H. Olufemi Odusote 2003)

It has been predicted that, $\mathrm{CO} 2$ injection into Coal beds not only improves the methane recovery but also help to maintain reservoir pressure and thus help in reducing operational costs. $\mathrm{CO} 2$ sequestration/ECBM production has been investigated in high-rank coals. Reservoir simulation studies and field tests are being conducted to assess CO2 sequestration potential and ECBM recovery in these coals. Below, I will discuss the characteristics of coal reservoirs, the 
$\mathrm{CO} 2$ sequestration/ECBM recovery process, key coal properties and field tests conducted in the San Juan basin in high-rank coals.

The theory of injecting $\mathrm{CO}_{2}$ or $\mathrm{N}_{2}$ into coal bed methane wells to enhance production was shown to be technically viable in a DOE project involving BP, Advanced Resources International (ARI), and Burlington Resources. In late 2002, Reeves and Schoeling, and Reeves published papers detailing the results of two pilot tests in the San Juan Basin where $\mathrm{CO}_{2}$ and $\mathrm{N}_{2}$ were injected. They concluded that the project has demonstrated that both $\mathrm{CO}_{2}$ and $\mathrm{N}_{2}$ injection can significantly improve methane gas recovery from coal seams. They also demonstrated that the complexity of injecting carbon dioxide or Nitrogen into Dual Porosity Coal bed methane reservoir could be successfully modeled using the existing numerical simulator available in the market. (Scott Reeves 2002)

Coal natural gas reservoirs are considered to be dual-storage systems. Coal bed methane reservoirs are typically modeled with dual-porosity/single-permeability characteristics when forecasting well or field performance. The relatively impermeable primary porosity system is dominated by adsorption/desorption phenomena, and mass transfer is controlled by diffusion, driven by gas-concentration gradients. The secondary porosity system is dominated by natural fractures, and flow through fractures is driven by pressure gradients between the fracture system and the production wells (Mathew J.Mavor 2002). Thus, coal-gas reservoirs are characterized by matrix (coal) and fracture (cleat) systems. In the production process with lowering of fluid pressure, gas desorbs from the coal into the matrix porosity, diffuses through the bulk matrix, and then flows into and through the fractures. During CO2 injection for carbon sequestration, the pathway for $\mathrm{CO} 2$ sorption is exactly reversed. (D. H. Olufemi Odusote et al 2003)

The CO2 sequestration/ECBM recovery process takes place when methane in the primary storage system is replaced with $\mathrm{CO} 2$, which adsorbs preferentially to the coal as compared to methane. This process increases methane production and stores $\mathrm{CO} 2$ in the coal. A sequestration project typically terminates when $\mathrm{CO} 2$ breaks through at the production wells after the majority of the well pattern has been swept.

A thorough knowledge of (1) sorption capacity, or isotherm behavior, of various gases and, (2) the changes in coal permeability with gas injection are critical for better understanding of $\mathrm{CO} 2$ sequestration/ECBM recovery processes.

Bromhal et al. studied the effects of sorption isotherms on $\mathrm{CO} 2$ sequestration in coal beds. 
The isotherm behavior is described by the Langmuir isotherm model to predict the amount of adsorbed/desorbed gas as a function of pressure. They concluded that not all of the in-situ methane will be produced and not all of the theoretical sequestration capacity will be used because CO2 does not reach all portions of the coal seam (Bromhal 2005).

In naturally fractured formations such as coal, permeability is sensitive to changes in effective stress. In coal bed methane reservoirs, matrix shrinkage or swelling occurs as a result of desorption or adsorption of gaseous species, which affects coal porosity and permeability. Palmer and Mansoori developed a model to calculate how absolute permeability and fracture porosity change as pressure decreases or increases in a reservoir, accounting for two important effects at the same time, stress-dependent permeability and matrix shrinkage/swelling. (I.Palmer,

\section{J. Mansoori December 1998)}

Reservoir simulators are being improved to include features that account for coal-matrix swelling from $\mathrm{CO} 2$ adsorption on coal, mixed-gas adsorption/desorption and diffusion, compaction/dilation of the natural fracture system under stresses, and non isothermal effects for gas injection. A comparison of numerical simulators for ECBM recovery with pure $\mathrm{CO} 2$ injection identified areas of improvement required to correctly model complicated mechanisms involved in the ECBM recovery process. (D.H.S. Law, Van der Meer, L.G.H, W.D.Gunture 2002)

The ECBM recovery process is being investigated in two field projects in the San Juan basin of New Mexico. One is the Allison Unit, operated by Burlington Resources Inc., into which $\mathrm{CO}_{2}$ is being injected, and second is the Tiffany Unit, operated by BP America Inc., into which $\mathrm{N}_{2}$ is being injected. These projects, funded by the Department of Energy (DOE) in a collaboration agreement with industry, are testing the process in high-rank coal beds. (S.R.Reeves July 2003)

Adequate field projects have not been currently done on sequestering $\mathrm{CO}_{2}$ into central Appalachian basin coals. Typical depressurizing methods are being followed in these high rank coals to extract coal bed methane, which indicates that there is significant coal bed methane left behind. There is high potential for re-considering the abandoned coalfields for sequestering $\mathrm{CO}_{2}$ and producing the unexploited methane. Thus, in this study, reservoir data have been collected using extensive literature review to accurately model the central Appalachian basin coals and conduct reservoir characterization and reservoir simulation to assess the potential for $\mathrm{CO}_{2}$ sequestration in, and enhance methane production from the Appalachian Coals. 


\subsection{SEAM POCAHONTAS}

The Pocahontas No.3 coal bed is one of the most studied coal beds in the Appalachian Basin coal region. The Pocahontas No.3 coal bed is within the Lower Pennsylvania Pocahontas Formation of the Pottsville Group. Where greater than $1.17 \mathrm{ft}$ (14 in) in thickness, it underlies all or parts of Wyoming, McDowell, and Raleigh, summers, Mercer, Greenbrier, and Fayette Counties in West Virginia, and parts of Wise, Dickenson, Buchanan, Scott, Russell, and Tazewell Counties in adjacent Virginia, an area within the central part of the Appalachian Plateaus (figure 2). The eastern limit of the coal bed is along the Allegheny structural front. The western minable limit of the coal bed is in the subsurface and was selected where the thickness of the coal bed is less than $1.17 \mathrm{ft}$ (Wood and others, 1983). The Pocahontas No.3 coal bed is, in general, a high-rank, lowvolatile bituminous (fig. 3), low-ash, low-sulfur coal that was once considered a standard for metallurgical coal (McColloch, 1995). Coal was first produced from the Pocahontas No. 3 coal bed in southwestern Virginia and southern West Virginia in 1882 and 1883, respectively (Rehbein and others, 1981; Hibbard, 1990). The resource model prepared for this assessment indicates that, of the original 7.2 billion short tons of Pocahontas No. 3 coal, 5.1 billion short tons remain (table 1); however, most of these resources, however, are in the inferred or hypothetical categories. The remaining resources are generally thinner, deeper, and more costly to mine than the coal that has already been mined.

The Pocahontas basin of southern West Virginia and southwestern Virginia is generally defined by the extent of the Lower Pennsylvanian Pocahontas Formation in the Pottsville Group within the central Appalachian Plateaus (Englund, Windolph, and Thomas, 1986).

The Pocahontas Formation contains 13 named coal beds in southern West Virginia, and at least 8 named coal beds in Virginia, including the Pocahontas No. 1 to No. 7 coal beds 


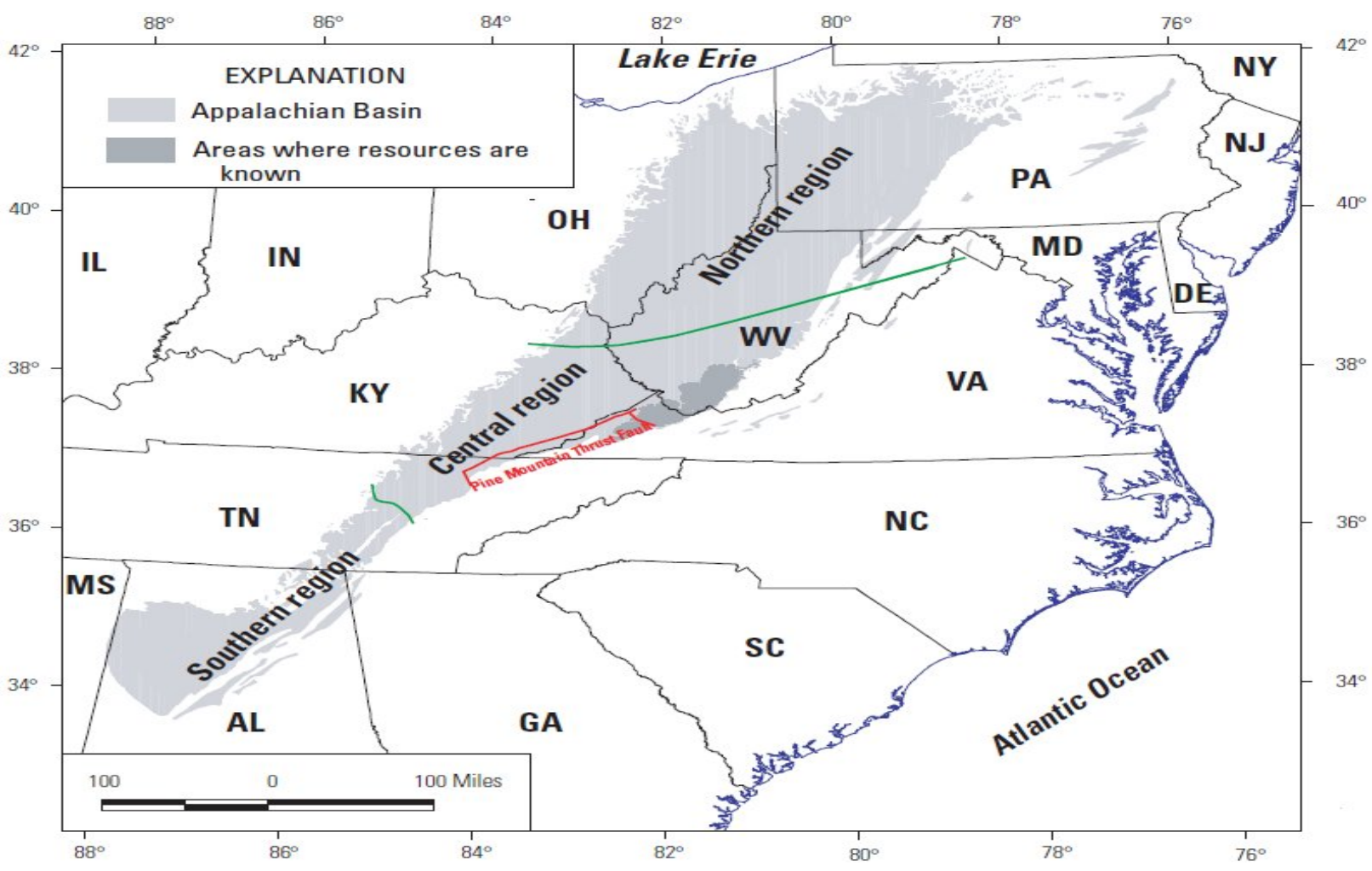

Figure 2.6: Map showing the location of northern, central and southern coal regions in the Appalachian Basin. The Seam Pocahontas No.3 coal beds occur in the central Appalachian basin.

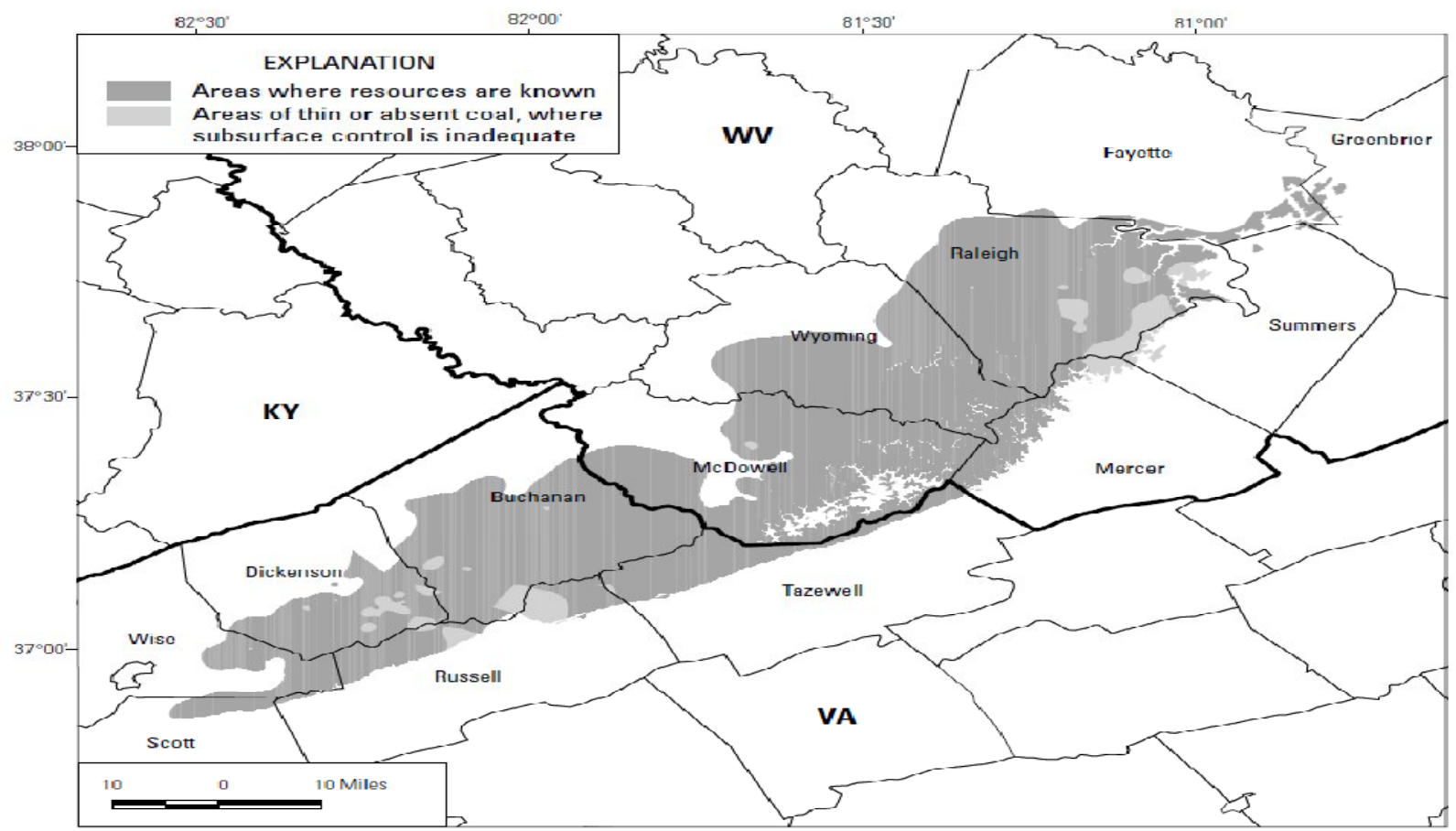

Figure 2.7: Map showing the areal extent of the Pocahontas No.3 coal bed, which extends through 12 counties in Virginia and West Virginia. 


\subsubsection{Geology of the Pocahontas Basin}

The Pocahontas basin is within the western margin of the folded and faulted Appalachians. The basin was deformed during the Alleghanian (post-Permian) orogenic phase of Appalachian mountain building. In Virginia, the Pocahontas No. 3 coal bed is adjacent to and on the Pine Mountain block (fig. 1) and arches over the nose of the Powell Valley anticline. The Pine Mountain block is a superficial structure that overlies a devolvement in the Devonian and Silurian strata below ( Harris and Milici, 1977). In nearby West Virginia, the coal bed is folded into several low-amplitude, but conspicuous, anticlines and synclines. The largest of these folds, the Dry Fork anticline, brings the coal bed to the surface in the southeastern part of the Pocahontas basin. All of these surficial structures are related to the latest Paleozoic deformation of the mountain chain, which in many places resulted in tangential shortening of the uppermost strata above a devolvement in the shale or salt formations. 


\section{CHAPTER 3 \\ METHODOLOGY}

\subsection{GOALS}

There are two primary goals in simulating injection of Carbon dioxide for sequestration and Enhanced coal bed methane recovery. First, through reservoir simulation, likely values of CO2 injection, methane production and $\mathrm{CO} 2$ breakthrough time are to be determined. This would provide an insight on the impact of uncertain parameters on the balance between $\mathrm{CO} 2$ sequestration and Methane production for Coal field. The second goal is to determine the relative importance various operational parameters in the Methane production and $\mathrm{CO} 2$ sequestration, thus to identify the parameters critical to the success of large- scale $\mathrm{CO} 2$ sequestration in the Central Appalachian basin.

\subsection{METHODOLOGY}

\subsubsection{Compilation of the Simulation Data Set}

A literature study was performed to choose an appropriate reservoir simulator. Law et al. at the Alberta Research Council (ARC) compared five different reservoir simulators available in the market for numerical modeling of Enhanced Coal bed methane recovery, namely GEM, SIMED II, COMET 2, ECLIPSE and GCOMP. The only essential requirement in a numerical simulator for this project is the ability to model $\mathrm{CO} 2$ injection and Methane production for dual porosity coal bed methane reservoirs. Law et al. proposed two problems and the results from all five commercial numerical simulators were compared. All five numerical simulators were able to model the proposed problems and the results matched very closely. However, I chose Schlumberger ECLIPSE numerical simulator for this study due to its extended accessibility in the Petroleum and Natural Gas Engineering labs at West Virginia University.

ECLIPSE 300 is a compositional model capable of modeling dual porosity coal bed methane reservoirs. It is also capable of modeling both mixed gas diffusion and noninstantaneous diffusion rates. Thus, I felt ECLIPSE 300 would be the most convenient numerical simulator to use for this study. 
I began to build a dataset for simulation of $\mathrm{CO} 2$ injection and Methane production for Central Appalachian Basin. In order to do this, I gathered relevant data from published literature. Most of the data used in this study came from Creties D.Jenkins (2008), S.D.Mohaghegh (2005), J.R.Kelafant (1988), Reinaldo J. Gonzalez (2006), Sinisha A Jikich (2004).

To quantify the uncertainty associated with the simulation predictions, the parameters most likely to impact the $\mathrm{CO} 2$ sequestration and Methane production activities were also identified from the literature and then, I determined the high, low and most likely values for the reservoir parameters (Table 1), based on information available from the literature.

The importance of coal properties and operational parameters on the production profiles has been demonstrated from previous studies. Some of them were SPE 78691 by W.Neal et al, SPE 84423 by Duane H.Smith et al, F.Burcu Gorucu et al, Saikat Mazumder et al. etc. Their works indicate that permeability, Langmuir pressure, Langmuir volume, porosity, water saturation and fracture spacing have great effect on Carbon dioxide injection and methane recovery. On the other hand, these parameters acquired from different sources contain uncertainty. Thus I decided to use them as my uncertain geological parameters in the study.

The base case data set for the Appalachian Basin coals is given in table 2.1. The most likely value of these parameters was used in the base case simulation. The following table 2.2, gives the ranges of the parameters of interest for this study and the distribution used to sample them.

Table 2.1: Static coal reservoir parameters used in the study

\begin{tabular}{|l|l|}
\hline Coal Thickness & $30 \mathrm{ft}$ \\
\hline Depth & $2000 \mathrm{ft}$ \\
\hline Fracture Compressibility & $100 \mathrm{e}^{-6} 1 / \mathrm{psi}$ \\
\hline Coal Density & $89.5 \mathrm{lb} / \mathrm{cu} \mathrm{ft}$ \\
\hline Reservoir Pressure & $1100 \mathrm{psia}$ \\
\hline Reservoir Temperature & $113^{\circ} \mathrm{F}$ \\
\hline Water Viscosity & $0.6 \mathrm{cp}$ \\
\hline Water Density & $61.8 \mathrm{lb} / \mathrm{cu} \mathrm{ft}$ \\
\hline
\end{tabular}


Table 2.2: Uncertain reservoir property estimates and design parameters

\begin{tabular}{|c|c|}
\hline Fracture porosity ${ }^{(1)}$ & $\mathrm{N}(0.005,0.002)$ \\
\hline \multicolumn{2}{|l|}{ Fracture Permeability ${ }^{(2)}$} \\
\hline $\mathrm{X}$ direction & $0.01,10,26 \mathrm{md}$ \\
\hline$Y$ direction & $0.005,5.5,13 \mathrm{md}$ \\
\hline $\mathrm{Z}$ direction & $0.0004,1,5 \mathrm{md}$ \\
\hline Fracture Spacing ${ }^{(2)}$ & $1,3,5$ inch \\
\hline Langmuir Pressure, $\mathrm{CO}_{2}{ }^{(2)}$ & $200,300,400$ psia \\
\hline Langmuir Pressure, $\mathrm{CH}_{4}{ }^{(2)}$ & $100,150,250 \mathrm{psia}$ \\
\hline Langmuir Volume, $\mathrm{CO}_{2}{ }^{(2)}$ & $0.8,1.5,1.57 \mathrm{Mscf} / \mathrm{ton}$ \\
\hline Langmuir Volume, $\mathrm{CH}_{4}{ }^{(2)}$ & $0.262,0.6,0.627 \mathrm{Mscf} / \mathrm{ton}$ \\
\hline Water Saturation ${ }^{(2)}$ & $60 \%, 65 \%, 75 \%$ \\
\hline $\mathrm{CO} 2$ injection rate & $1000,2000,3000,4000 \mathrm{Mscf} / \mathrm{day}$ \\
\hline Well Spacing & $40,80,160,240$ acres \\
\hline Well pattern & Inverted 5-spot, Inverted 7-spot \\
\hline \multicolumn{2}{|c|}{ (1) Normal distribution } \\
\hline
\end{tabular}

Fracture porosity $[0.005,0.002]$ : The average fracture porosity for the coals in the central Appalachian basin is approximately 0.004. A normal distribution (Mean- 0.005 and Standard deviation- 0.002) is used in the reservoir simulation model to help quantify uncertainty.

Coal thickness: Coal thickness of $30 \mathrm{ft}$ is found to be the representative value in the study area. (Sinisha A Jikich 2004)

Fracture Spacing [1, 3, 5 inch]: Coal fracture/cleat spacing was estimated to be approximately 3 inch on the basis of coal descriptions of Central Appalachian basin. Fracture spacing's are used to calculate the matrix-to-fracture transfer coefficient as described by the shape factor type. (J.R.Kelafant 1988) 
Coal permeability: A triangular distribution of coal fracture permeability based on well test results (PermX - 0.01, 10, $26 \mathrm{md}),($ PermY - 0.005, 5.5, $13 \mathrm{mD})$, (PermZ- 0.0004,1,5) is used in the reservoir simulation modeling. (J.R.Kelafant 1988), (Sinisha A.Jikich 2003), (X.R.Wei 2006), (S.D.Mohaghegh 2005)

Rock compressibility: A matrix compressibility of $1 \times 10^{-7} \mathrm{psi}^{-1}$ and a fracture compressibility of $100 \times 10^{-6} \mathrm{psi}^{-1}$ are used in the simulation model.

Coal density: Bulk density of the coal used in this study was $89.5 \mathrm{lb} / \mathrm{cu} \mathrm{ft}$. (Sinisha A.Jikich 2003)

Isotherm parameters: A triangular distribution of all the isotherm parameters namely langumiur pressure of CO2( 200, 300, 400 psia), Langmuir pressure of $\mathrm{CH} 4(100,150,250)$, Langmuir volume of $\mathrm{CO} 2(0.8,1.5,1.57 \mathrm{Mscf} / \mathrm{ton})$ and finally, Langmuir volume of $\mathrm{CH} 4(0.262,0.6,0.627$ Mscf/ton) were used in the simulation model. The minimum, maximum and mode values for each of these isotherm parameters were obtained from the literature. (Sinisha A Jikich 2004), (J.R.Kelafant 1988), (D. H. Olufemi Odusote 2003)

Reservoir pressure and temperature: The typical reservoir temperature for the central Appalachian basin coals is $113^{\circ} \mathrm{F}$ and pressure is around 1100 psia.

Operation constraints: Operating conditions for the producers in the model are controlled, primarily, by the minimum constant bottom hole flowing pressure of $150 \mathrm{psia}$, and secondarily, bythe maximum gas production rate of $882.5 \mathrm{Mcf} / \mathrm{D}$, for both base case scenarios (5-spot and 7spot). For the injector wells, maximum bottom hole injection pressure is 2,175 psia and the secondary constraint was the respective injection rates for different cases. 


\subsubsection{Pattern Reservoir Model}

A reservoir simulation model that is one fourth of the inverted 5-spot pattern is modeled using the compositional model in Eclipse 300 (Figure 3.1) in order to run both the deterministic and probabilistic simulations. A reservoir simulation model that is one twelfth of the inverted 7-spot pattern was also modeled using the Eclipse numerical simulator, developed by Schlumberger (Figure 3.2). Note that the predicted volumes of $\mathrm{CO} 2$ sequestered and $\mathrm{CH} 4$ produced are scaled to a full pattern in this thesis.

A grid sensitivity study was performed by redefining the grid system from $21 \times 21 \times 2$ where the grid block magnitude is $1320 \mathrm{ft} \times 1320 \mathrm{ft} \times 30 \mathrm{ft}$ and the singe grid block magnitude is 62.85 $\mathrm{ft}$ to $60 \times 60 \times 2$ grid system where the single grid block magnitude is $22 \mathrm{ft}$ in an inverted 5-spot pattern with 80 acre well spacing. Comparison of saturation and pressure distributions, recovery efficiency, and production and injection performances of wells indicated no negative impacts resulting from use of the $21 \times 21 \times 2$ grid model, allowing us to use it with confidence. Results for these two cases are shown in Fig. 3.3. Differences in cumulative $\mathrm{CO} 2$ injection and $\mathrm{CH} 4$ production are very meager indicating that the grid size did not have significant effect on the Cumulative $\mathrm{CO} 2$ injection and $\mathrm{CH} 4$ production performance. The computer time is reduced by a factor of 6 when using the $21 \times 21 \times 2$ grid model. Thus, I performed my runs using the $21 \times 21 \times$ 2 grid cells for all my cases in this study. 


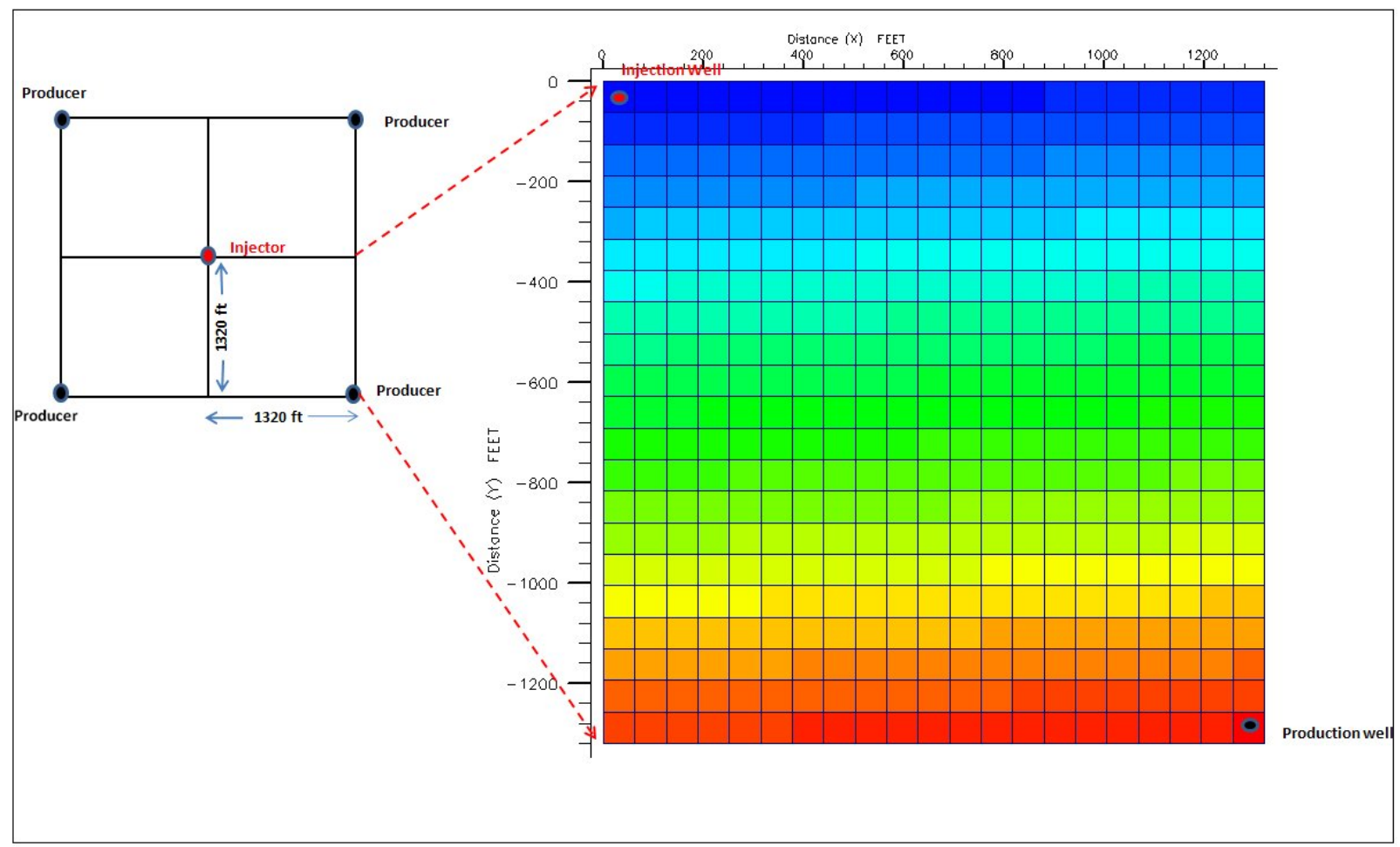

Figure 3.1: Cartesian, Grid model of 1/4 inverted 5-spot pattern, 80 acre well spacing

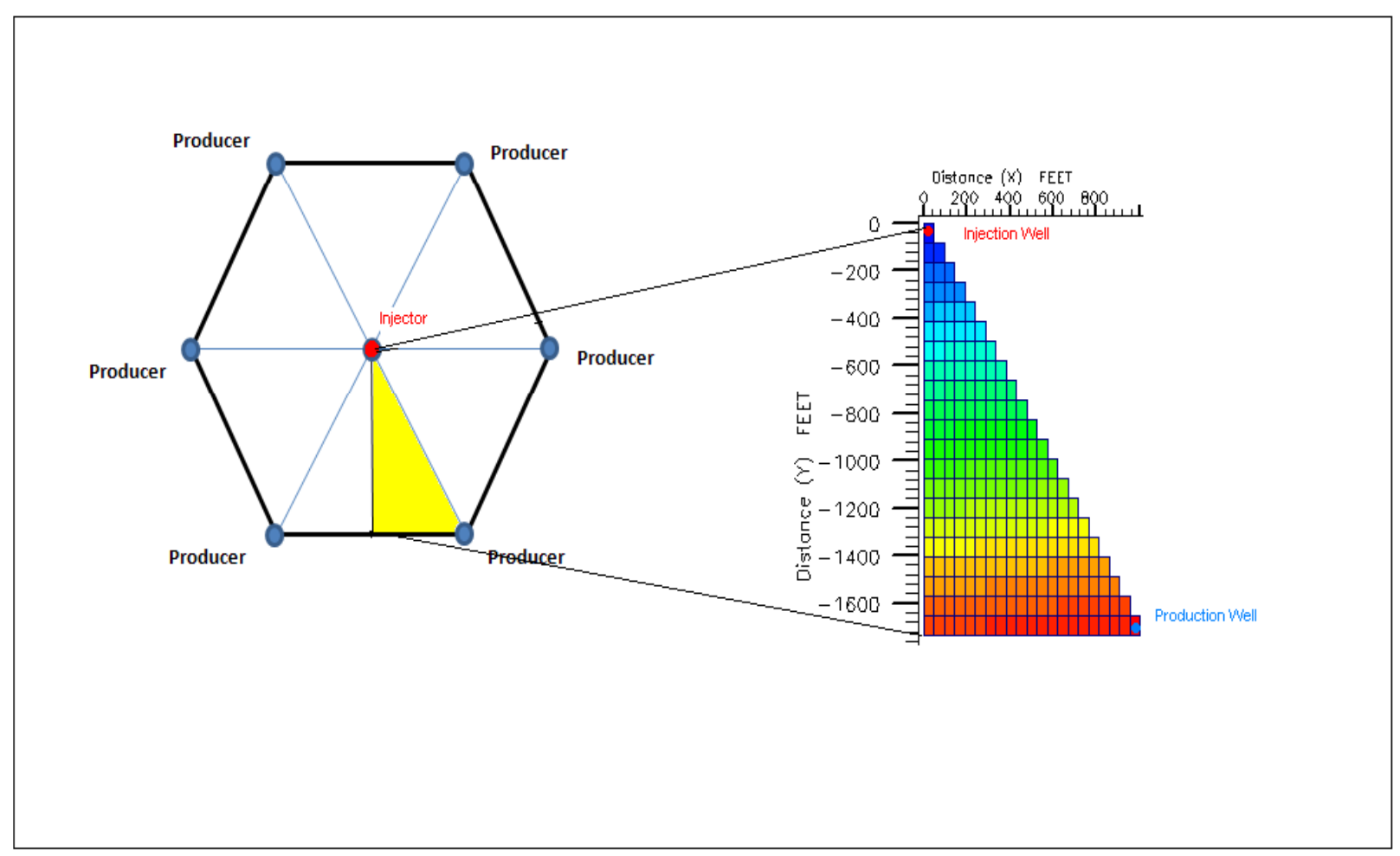

Figure 3.2: Cartesian grid model of 1/12 inverted 7-spot pattern, 80 acre well spacing 


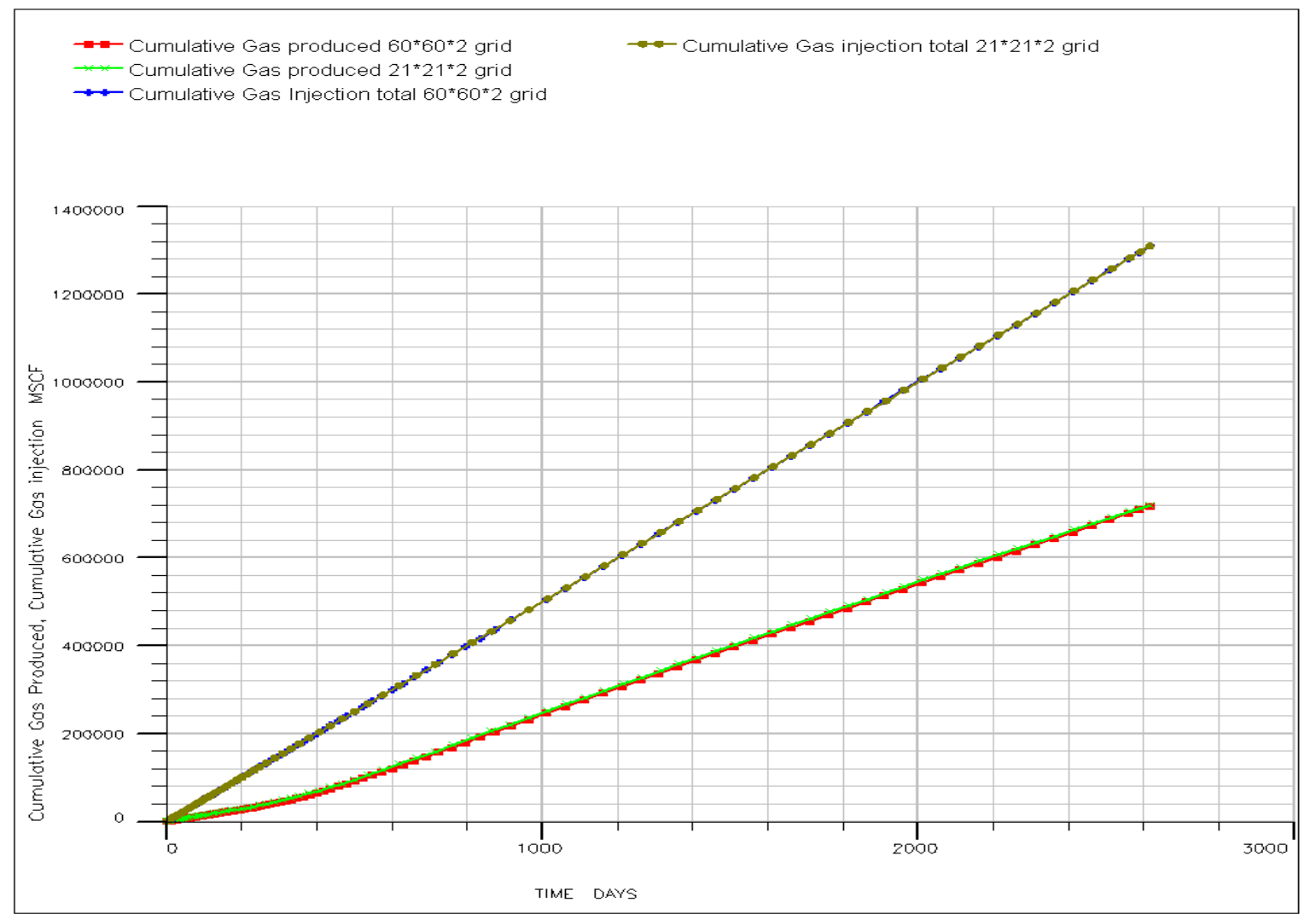

Figure 3.3: Grid sensitivity comparison results for cumulative $\mathrm{CO} 2$ injection and $\mathrm{CH} 4$ production profiles, two grid sizes

\subsubsection{Simulation Runs}

Once the base models had been set up, coupling Monte Carlo Simulation in Excel with the Eclipse numerical simulator was proceeded to carry out the probabilistic analysis. Since there are thousands of runs to account for, manually entering data into the Eclipse input file is extremely time consuming. Therefore, a computer program was developed using Visual Basic Application tool in Excel to perform the operation. 
The flowchart (figure 3.4) represents the various steps followed by the computer program in order to speed up the probabilistic analysis

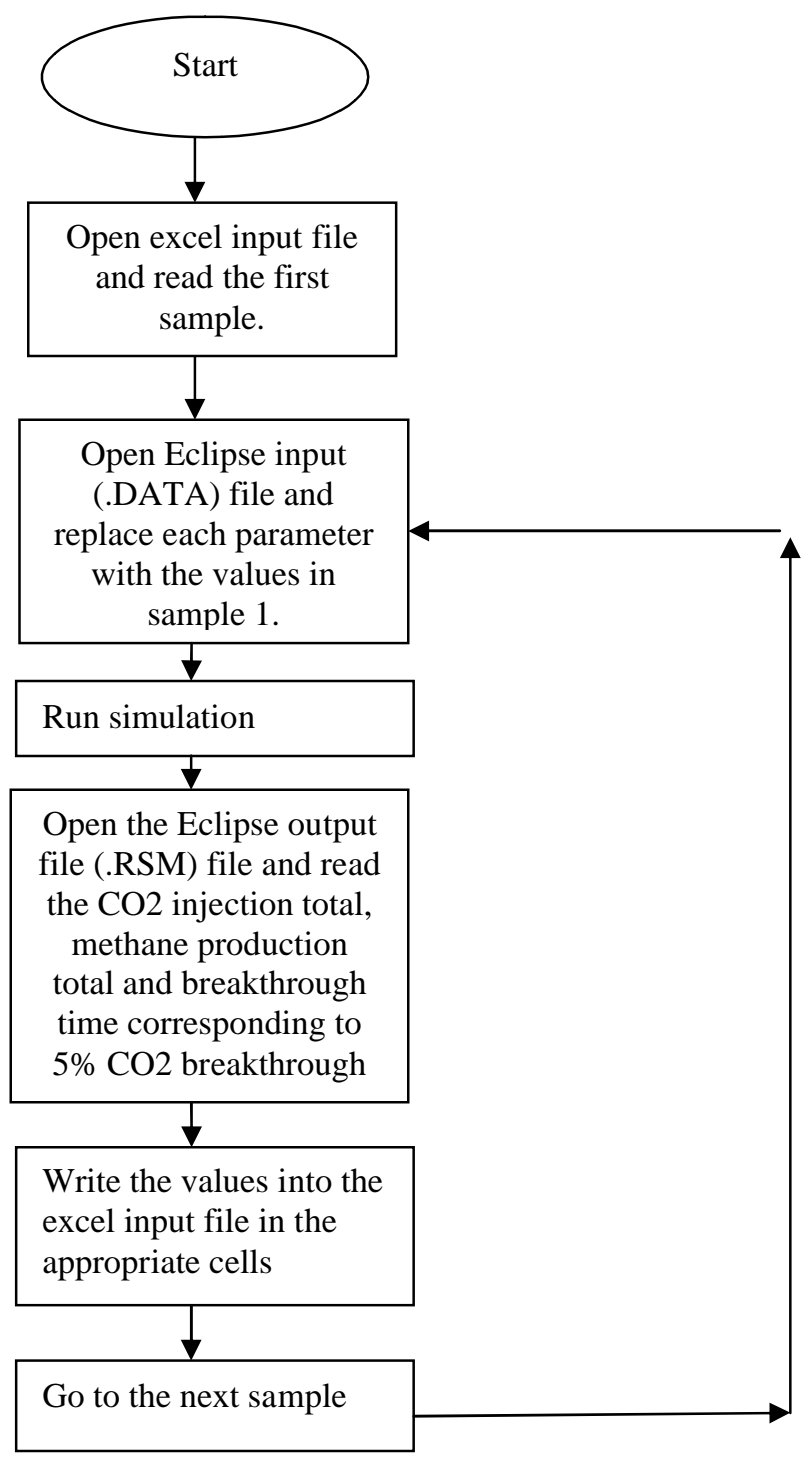

Figure 3.4: Flowchart showing the procedures of the computer program design

Over 1000 samples were created in the excel sheet for the uncertainty analysis using normal and triangular distributions of various reservoir parameters. Each sample consists of a value for porosity, permeability X, Y,Z, water saturation, Langmuir pressure (CO2 and $\mathrm{CH} 4)$, Langmuir volume $(\mathrm{CO} 2$ and $\mathrm{CH} 4)$ and sigma. Once this file is generated, the computer program transfers 
these reservoir parameters to the input file of the numerical simulator Eclipse for each run. After the simulation runs, the output file for each sample is opened and the parameters of interest namely $\mathrm{CO} 2$ injection total, $\mathrm{CH} 4$ production total and breakthrough time is picked up by the program and pasted into the excel file adjacent to the appropriate sample number. 


\section{CHAPTER 4}

\section{RESULT AND DISCUSSION}

To predict the uncertainties in injecting Carbon dioxide and Enhanced Coal bed methane production in the central Appalachian basin coal beds, I conducted simulations with three different operational scenarios or cases. These were 1) Sensitivity analysis of the effect of well pattern (inverted 5 spot and inverted 7 spot) on the methane production and $\mathrm{CO} 2$ sequestration potential. 2) Sensitivity study of the effect of well spacing on the Enhanced Coal bed methane production and $\mathrm{CO} 2$ injection. 3) Sensitivity study of the effects of various Carbon dioxide injection rates on ECBM production and $\mathrm{CO} 2$ injection total. There were also various statistical analysis performed on the base case scenario to evaluate the relative importance of various Coal bed properties like permeability, porosity, water saturation, pressure, Langmuir volume and fracture spacing on the production/injection behaviors namely cumulative methane production, cumulative Carbon dioxide injection and Break through time of $\mathrm{CO} 2$ (The time when $\mathrm{CO} 2$ reaches $5 \%$ in production well).

\subsection{RESERVOIR SIMULATION STUDIES}

\subsubsection{CO2 sequestration/ ECBM production Base Case Scenarios - Case (1a ) for 5-Spot Pattern}

To assess reservoir performance during CO2 sequestration in the Appalachian coals, I conducted probabilistic simulations (1000 iterations), modeling simultaneous injection of $100 \% \mathrm{CO} 2$ and production of $\mathrm{CH} 4$ under the base case operating conditions with an 80 -acre well spacing. The $\mathrm{CO} 2$ injection rate is $2000 \mathrm{Mscf} /$ day for an inverted 5 spot pattern (injection well in the middle and 4 production wells). Schlumberger Eclipse 300 compositional model was used to model $1 / 4^{\text {th }}$ of the inverted 5 spot pattern. The model is fully implicit, dual porosity model with Grid dimensions of $21 \times 21 \times 2$ and the size of grid block is $1320 \mathrm{ft}$ x $1320 \mathrm{ft}$ x $29.5 \mathrm{ft}$. Both the injector and producer begin operation at the start of simulation. The producer is first rate constraint and then pressure constraint to operate at 150 psia. Likewise, the injector is primarily rate constraint 
to operate at $2000 \mathrm{Mscf} / \mathrm{day}$ (Base case) and secondarily pressure constraint to operate at 2176 psia. Simulation ends when $\mathrm{CO} 2$ reaches $5 \%$ in the production stream.

The results of the modeling studies for the base case 1a scenario are shown in the following figures. Figure 4.1 shows, colorful maps of various reservoir properties at breakthrough, i.e., the time at which $\mathrm{CO} 2$ comprises $5 \%$ mole fraction of the produced gas.
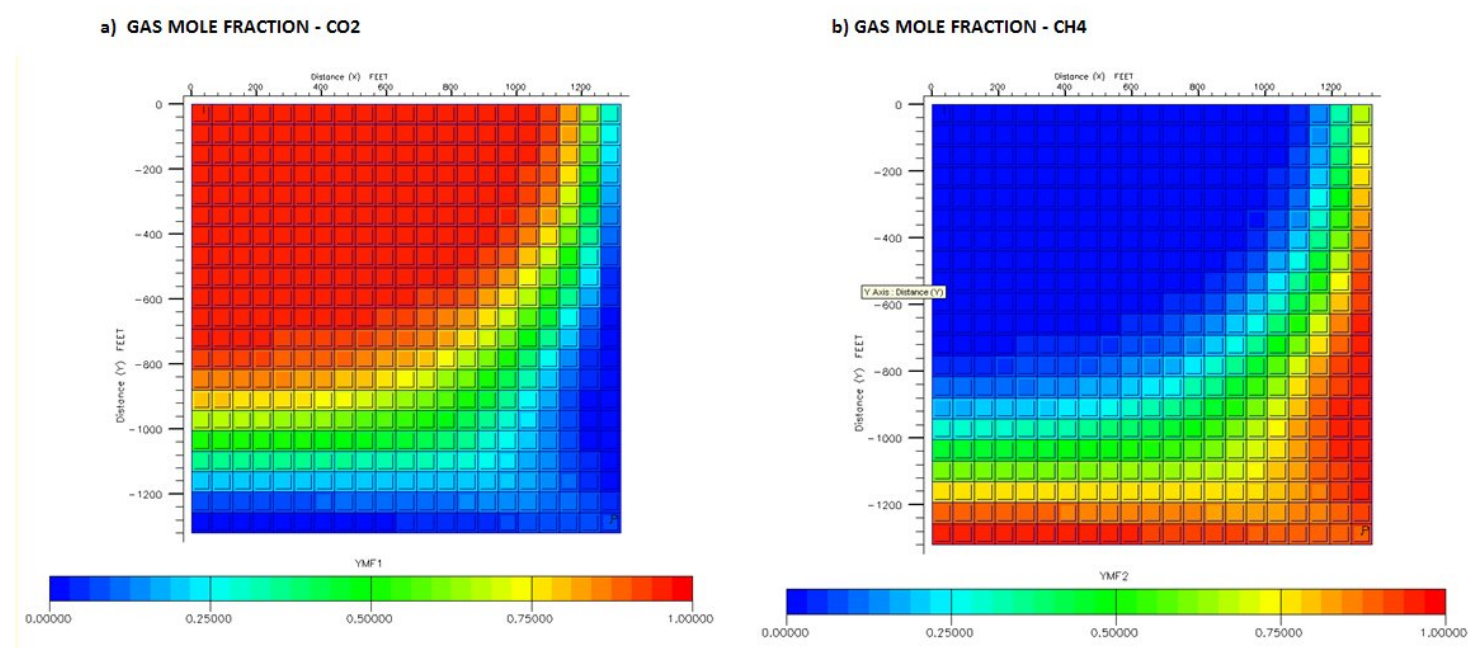

c) PRESSURE - FRACTURE (psia)

d) WATER SATURATION - FRACTURE
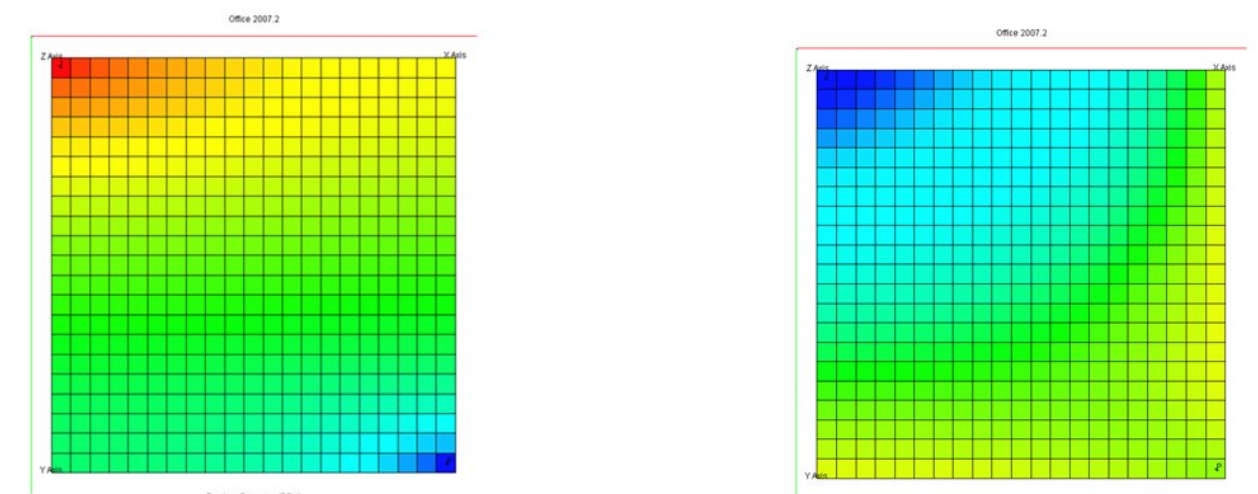

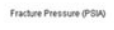


Figure 4.1: a) Carbon dioxide gas mole fraction, b) Methane gas mole fraction c) reservoir pressure at break point, and d) water saturation in the fracture system for one of the samples in the base case(1a) scenario of inverted 5 spot pattern, 80 acre well spacing and injection rate of $2000 \mathrm{Mscf} / \mathrm{day}$

The well performance of the base case (1a) has been analyzed in detail and various production of Methane and injection profiles of Carbon dioxide are represented in figures $4.2 \mathrm{a}, 4.2 \mathrm{~b}$ 


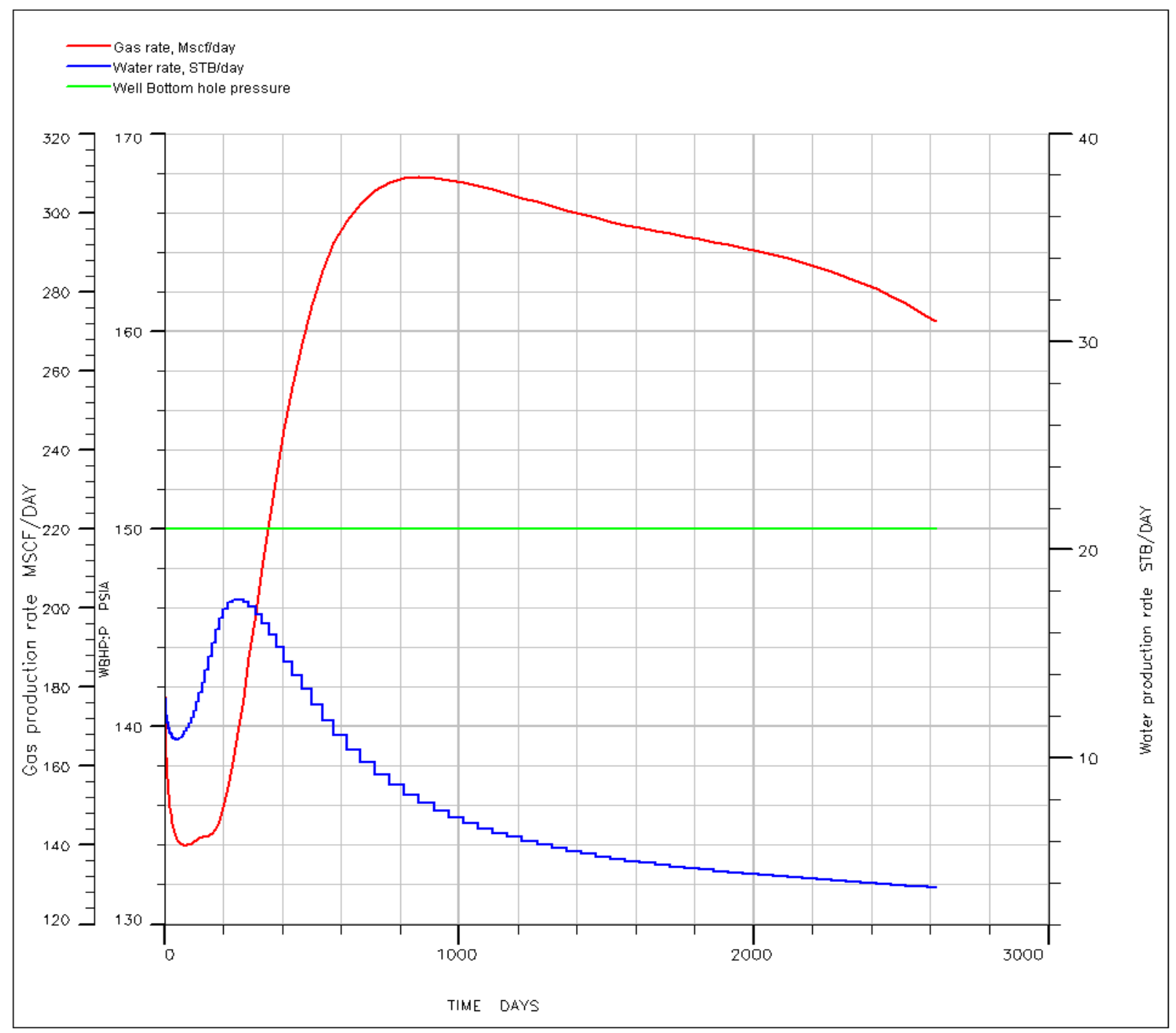

Figure 4.2a: Methane production rate, Water production rate and Well bottom hole pressure for the production well for $1 / 4$ of the base case (1a) 


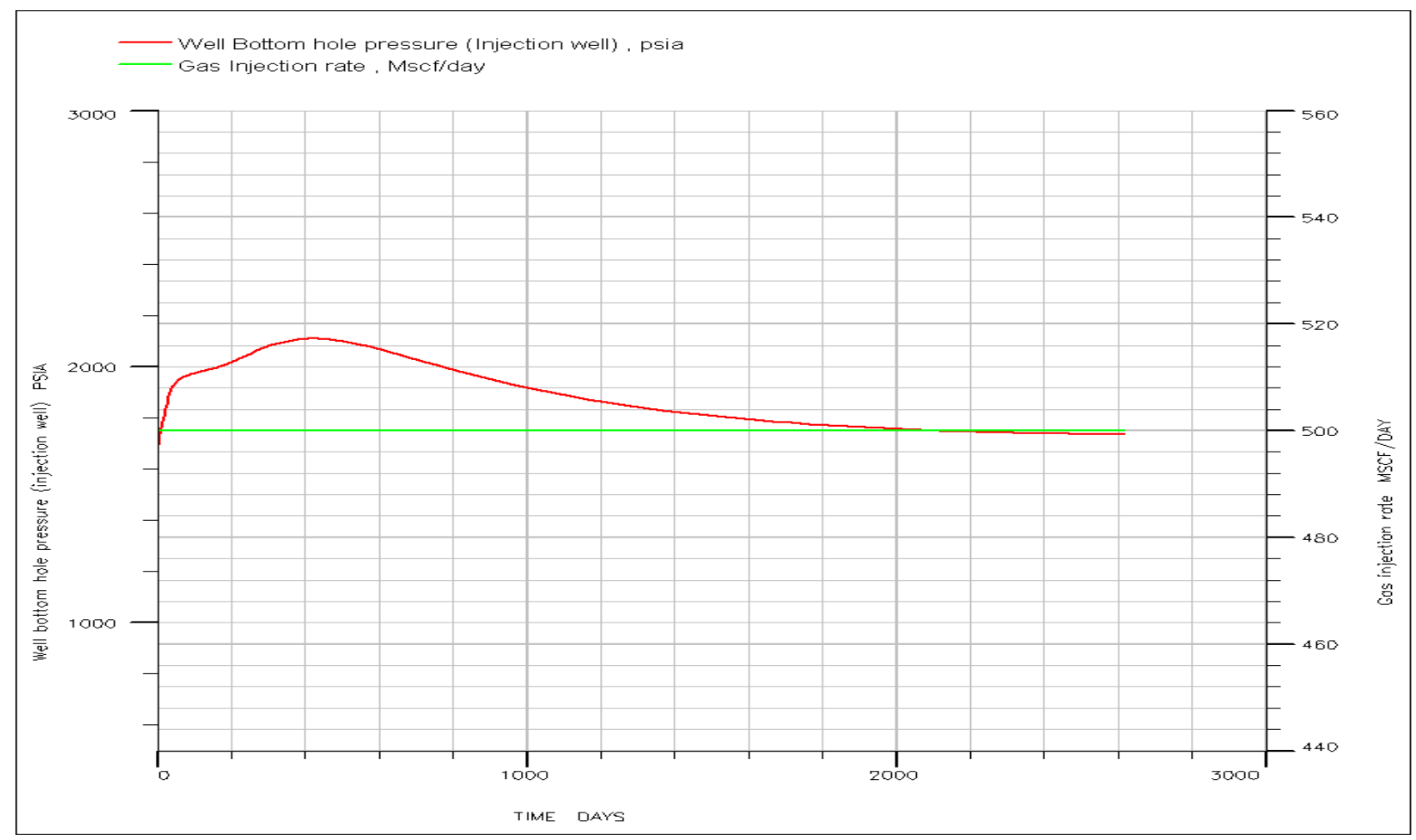

Figure 4.2b: Injection well bottom hole pressure for $1 / 4$ th base case scenario(1a)

\subsubsection{Cumulative CO2 injection Statistics for base case (1a)}

On conducting the probabilistic analysis for the base case (1a) scenario of 80 acre well spacing and inverted 5 spot pattern, simulation results of $100 \% \mathrm{CO} 2$ injection at an injection rate of 2000Mscf/day for 1000 samples from the central Appalachian basin coals indicate that on an average, the coals could most likely store $5.5 \mathrm{Bcf}$ of $\mathrm{CO} 2$ with coal bed methane recovery of $2.36 \mathrm{Bcf}$ and $\mathrm{CO} 2$ break through time of 2849 days which is roughly 8 years. The minimum, maximum, the mean and the values greater than 10, 50 and 90 percentiles for each parameter of interest are shown below where $10 \%$ being the least favorable, $90 \%$ the most favorable and $50 \%$ being the most likely value. Table 4.1 shows statistical analysis results for Cumulative CO2 injection total. 
Table 4.1: Cumulative CO2 injection Statistics for base case (1a)

\begin{tabular}{|c|c|}
\hline Minimum Value & $2.35 \mathrm{Bcf}$ \\
\hline Maximum Value & $8.15 \mathrm{Bcf}$ \\
\hline Mean Value & $5.5 \mathrm{Bcf}$ \\
\hline Standard Deviation & $1.22 \mathrm{Bcf}$ \\
\hline $90 \%$ probability value greater than & $7.09 \mathrm{Bcf}$ \\
\hline $10 \%$ probability value greater than & $3.95 \mathrm{Bcf}$ \\
\hline $50 \%$ probability value greater than & $5.65 \mathrm{Bcf}$ \\
\hline
\end{tabular}

\subsubsection{Cumulative $\mathrm{CH}_{4}$ production Statistics for base case (1a)}

The Cumulative methane production data was then analyzed. The relevant statistics are summarized in Table 4.2 below. The P90 value which is $2.84 \mathrm{Bcf}$ is the most favorable, P10 which is $1.9 \mathrm{Bcf}$ is the least favorable and P50 which is $2.37 \mathrm{Bcf}$ is the most likely value of methane production for the inverted 5 -spot pattern base case (1a).

Table 4.2: Cumulative Methane Production Statistics base case (1a)

\begin{tabular}{|c|c|}
\hline Minimum Value & $1.4 \mathrm{Bcf}$ \\
\hline Maximum Value & $3.37 \mathrm{Bcf}$ \\
\hline Mean Value & $2.36 \mathrm{Bcf}$ \\
\hline Standard Deviation & $0.35 \mathrm{Bcf}$ \\
\hline $90 \%$ Probability values greater than: & $2.84 \mathrm{Bcf}$ \\
\hline $10 \%$ Probability values greater than: & $1.9 \mathrm{Bcf}$ \\
\hline $50 \%$ probability value greater than & $2.36 \mathrm{Bcf}$ \\
\hline
\end{tabular}




\subsubsection{Statistical Analysis of Breakthrough time for base case (1a)}

The statistical analysis was performed on the breakthrough time for the base case for inverted 5spot pattern. Table 4.3 summarizes the various values for the breakthrough time.

Table 4.3: Breakthrough time statistics for base case (1a)

\begin{tabular}{|c|c|}
\hline Minimum Value & 1189 days \\
\hline Maximum Value & 4079 days \\
\hline Mean Value & 2853 days \\
\hline $90 \%$ Probability values greater than: & 3658 days \\
\hline $10 \%$ Probability values greater than: & 2027 days \\
\hline $50 \%$ probability value greater than & 2888 days \\
\end{tabular}

\subsubsection{CO2 sequestration/ ECBM production base case (1b): inverted 7-Spot Pattern}

The base case (1b) has the same operating conditions as base case (1a) except that the well pattern is an inverted 7-spot pattern instead of inverted 5-spot pattern. Just like base case (1a), in order to assess reservoir performance during $\mathrm{CO} 2$ sequestration in the Appalachian coals, I conducted probabilistic simulations (1000 iterations), modeling simultaneous injection of 100\% $\mathrm{CO} 2$ and production of $\mathrm{CH} 4$ under the base case operating conditions of an 80 -acre well spacing and $2000 \mathrm{Mscf} /$ day CO2 injection rate for the inverted 7 spot pattern (injection well in the middle and 6 production wells). Schlumberger Eclipse 300 compositional model was used to model $1 / 12$ of the inverted 7 spot pattern. The model is fully implicit, dual porosity model with Grid dimensions of $21 \times 21 \times 2$ and the grid size is $1003 \mathrm{ft} \times 1736 \mathrm{ft} \times 29.5 \mathrm{ft}$. Both the injector and producer begin operation at the start of simulation. The producer is primarily rate constraint and secondarily pressure constraint to operate at 150 psia. Likewise, the injector is primarily rate 
constraint to operate at $2000 \mathrm{Mscf} / \mathrm{day}$ (Base case) and secondarily pressure constraint to operate at 2176 psia. Simulation ends when $\mathrm{CO} 2$ reaches $5 \%$ in the production stream.

The results of the modeling studies for the base case (1b) are shown in the following figures. Figure 4.3 shows colorful maps of various reservoir properties at breakthrough, i.e., the time at which $\mathrm{CO} 2$ comprises $5 \%$ mole fraction of the produced gas.

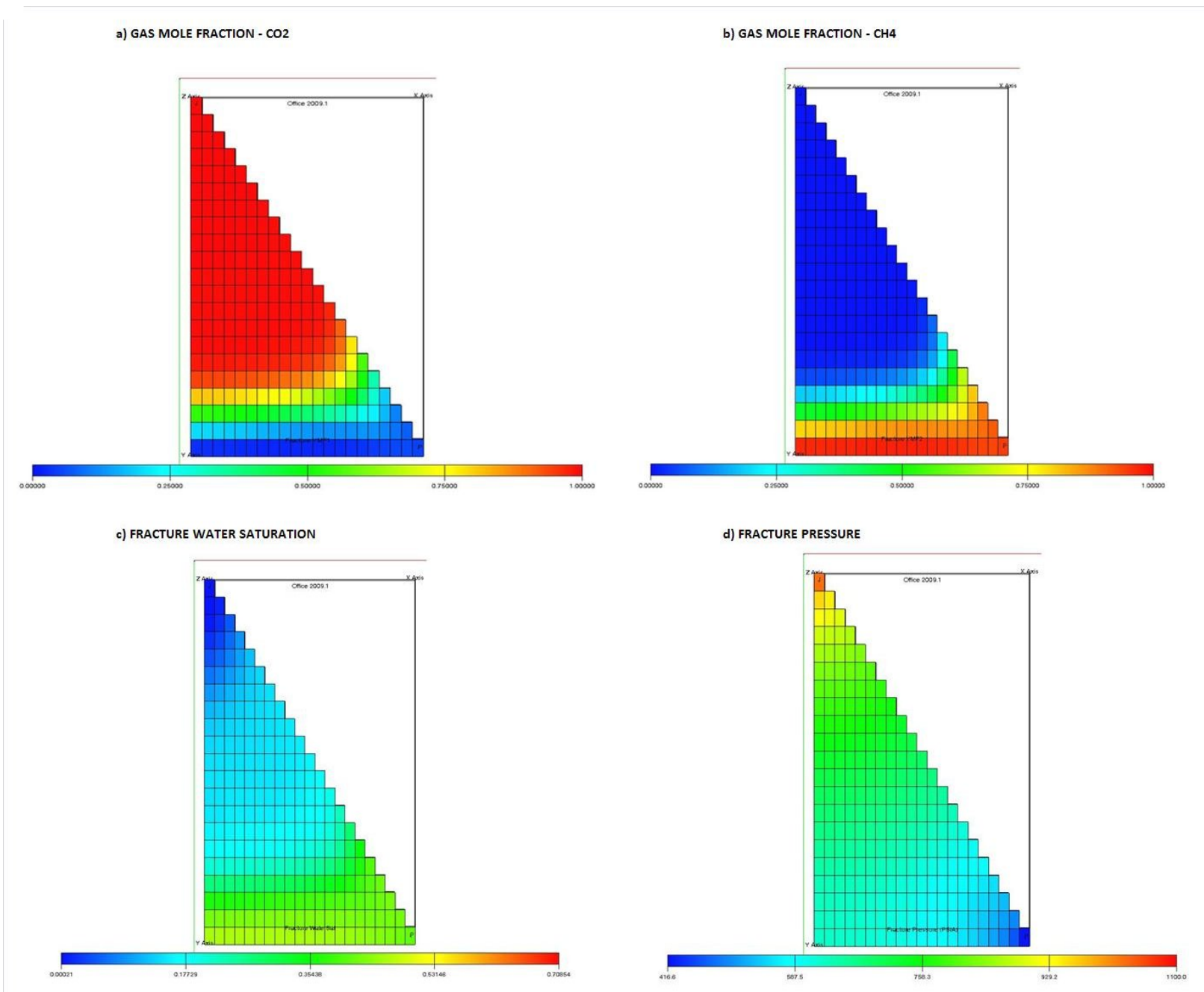

Figure 4.3: a) Methane gas mole fraction, b) Carbon dioxide gas mole fraction, c) water saturation in the fracture system, and d) reservoir pressure at break point for one of the samples in the base case(1b) of inverted 7 spot pattern, 80 acre well spacing and injection rate of $2000 \mathrm{Mscf} / \mathrm{day}$

The well performance of the base case (1b) has been analyzed in detail using the Eclipse numerical simulator and various production and injection profiles of Methane and Carbon 
dioxide simultaneously are represented in figures $4.4 \mathrm{a}$, and $4.4 \mathrm{~b}$. Figure $4.4 \mathrm{a}$ shows the methane production rate and water production rates for 1/12 of inverted 7-spot pattern, followed by figure $4.4 \mathrm{~b}$, which show the injection profiles.

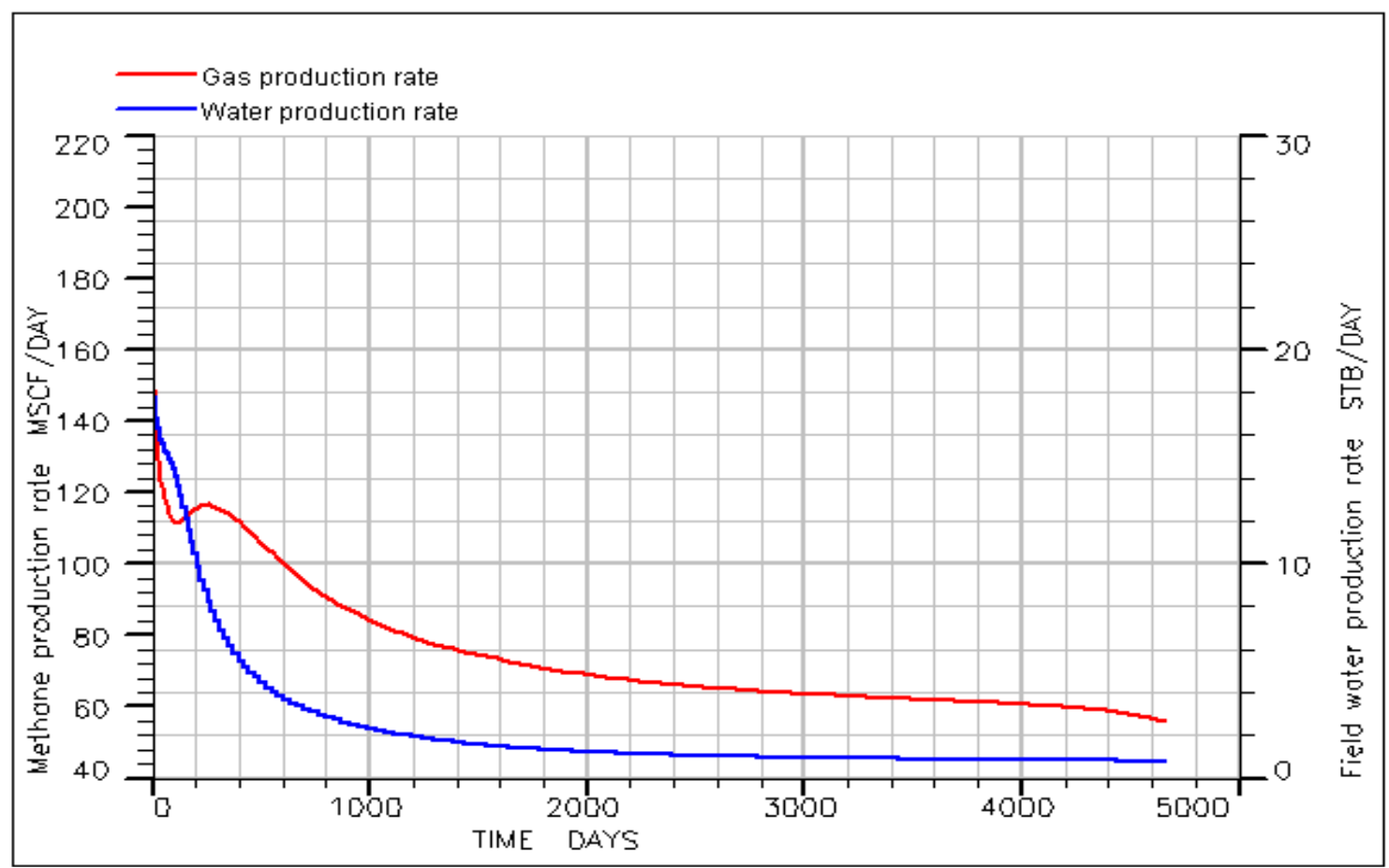

Figure 4.4a: Methane production rate and Water production rate for 1/12 of inverted 7-spot pattern base case (1b)

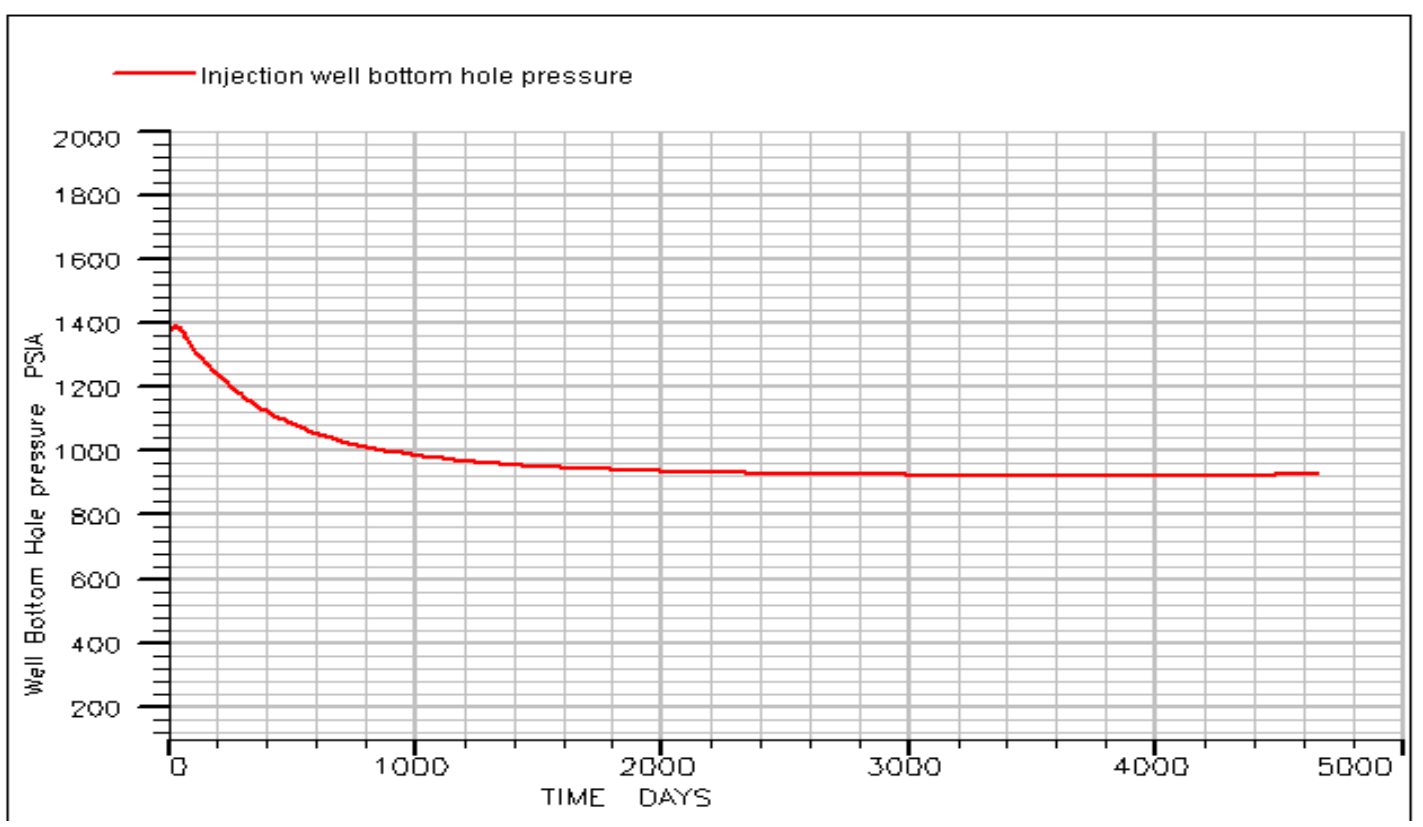

Figure 4.4b: Injection well bottom hole pressure for $1 / 12$ of inverted 7 -spot pattern base case (1b). 


\subsubsection{Cumulative CO2 injection Statistics of Base Case (1b)}

On conducting the probabilistic analysis for the base case (1b) of 80 acre well spacing and inverted 7 spot pattern, simulation results of $100 \% \mathrm{CO} 2$ injection at an injection rate of 2000Mscf/day for 1000 samples from the central Appalachian basin coals indicate that on an average, the coals could most likely store $9.8 \mathrm{Bcf}$ of $\mathrm{CO} 2$ with coal bed methane recovery of 4.7 Bcf and CO2 breakthrough time of 4963 days which is roughly 14 years. The minimum, maximum, the mean and the values greater than 10, 50 and 90 percentiles are shown below where $10 \%$ being the least favorable, $90 \%$ the most favorable and $50 \%$ being the most likely value. Table 4.4 shows statistical analysis results for Cumulative $\mathrm{CO} 2$ injection total.

Table 4.4: Cumulative CO2 injection Statistics for inverted 7-spot pattern with 80 acre well spacing and 2000 Mscf/day CO2 injection rate: Base Case (1b)

\begin{tabular}{|c|c|}
\hline Minimum Value & $4.37 \mathrm{Bcf}$ \\
\hline Maximum Value & $15.73 \mathrm{Bcf}$ \\
\hline Mean Value & $9.86 \mathrm{Bcf}$ \\
\hline Standard Deviation & $1.96 \mathrm{Bcf}$ \\
\hline $90 \%$ probability value greater than & $12.24 \mathrm{Bcf}$ \\
\hline $10 \%$ probability value greater than & $7.19 \mathrm{Bcf}$ \\
\hline $50 \%$ probability value greater than & $10.02 \mathrm{Bcf}$ \\
\hline
\end{tabular}




\subsubsection{Cumulative CH4 production Statistics for Base Case (1b)}

The Cumulative methane production data was then analyzed. The relevant statistics are summarized in Table 4.2 below. The P90 value which is $5.66 \mathrm{Bcf}$ is the most favorable, P10 which is $3.7 \mathrm{Bcf}$ is the least favorable and P50 which is $4.83 \mathrm{Bcf}$ is the most likely value of methane production for the inverted 7-spot pattern base case (1b).

Table 4.5: Cumulative Methane Production Statistics for base case (1b)

\begin{tabular}{|c|c|}
\hline Minimum Value & $2.79 \mathrm{Bcf}$ \\
\hline Maximum Value & $6.26 \mathrm{Bcf}$ \\
\hline Mean Value & $4.75 \mathrm{Bcf}$ \\
\hline $90 \%$ Probability values greater than: & $5.66 \mathrm{Bcf}$ \\
\hline $10 \%$ Probability values greater than: & $3.7 \mathrm{Bcf}$ \\
\hline $50 \%$ probability value greater than & $4.83 \mathrm{Bcf}$ \\
\hline
\end{tabular}

\subsubsection{Statistical Analysis of Break through time (base case 1b)}

The statistical analysis was performed on the breakthrough time for the base case scenario for inverted 7-spot pattern. Table 4.6 summarizes the various mean, P10, P50, P90 values for the breakthrough time.

Table 4.6: Breakthrough time statistics for base case (1b)

\begin{tabular}{|c|c|}
\hline Minimum Value & 2175 days \\
\hline Maximum Value & 8072 days \\
\hline Mean Value & 4963 days \\
\hline Standard Deviation & 1015 days \\
\hline $90 \%$ Probability values greater than: & 6179 days \\
\hline
\end{tabular}




\begin{tabular}{|c|c|}
\hline $10 \%$ Probability values greater than: & 3597 days \\
\hline $50 \%$ probability value greater than & 5035 days \\
\hline
\end{tabular}

\subsubsection{Sensitivity Study of the Effects of Well Spacing (Inverted 5 spot pattern)}

To determine the effects of well spacing on the performance of coal bed reservoir during $\mathrm{CO} 2$ sequestration and ECBM production, I conducted probabilistic simulation modeling studies of 1000 iteration of $100 \% \mathrm{CO} 2$ gas injection under the base case operating conditions for 40, 80 , 160 and 240-acre well spacing for the inverted 5 spot pattern. These simulation studies were performed while the $\mathrm{CO} 2$ injection rate was maintained constant. The various $\mathrm{CO} 2$ injection rates which were used for the study were 1000, 2000, 3000, 4000 Mscf/day. For example, for an injection rate of $1000 \mathrm{Mscf} / \mathrm{day}$, simulation was performed for all different well spacing cases and thus the results were compared. These simulation studies are illustrated in the Figures 4.5 4.8

Figure 4.5 shows the cumulative distribution functions for the volumes of $\mathrm{CO} 2$ sequestered, $\mathrm{CH} 4$ produced and breakthrough times respectively for an inverted 5-spot pattern and $1000 \mathrm{Mscf} /$ day CO2 injection rate. Mean values of the estimated volumes of $\mathrm{CO} 2$ that can be sequestered in Central Appalachian basin coals under the above mentioned operating conditions are 2.67, 6.06, 11.45 and $16.8 \mathrm{Bcf}$ for 40,80, 160 and 240- acre well spacing respectively in an inverted 5-spot pattern. The corresponding $\mathrm{CH}_{4}$ production values are 1.27, 2.9, 5.5, 8.2 Bcf, at breakthrough times of 2674, 6064, 11471 and 16866 days respectively.

The Cumulative distribution function graphs clearly indicate increased $\mathrm{CO} 2$ sequestration and $\mathrm{CH} 4$ production with increasing well spacing. The same analysis was then performed for various injection rates like 2000, 3000 and $4000 \mathrm{Mscf} /$ day injection rates and the effect of well spacing was studied. 


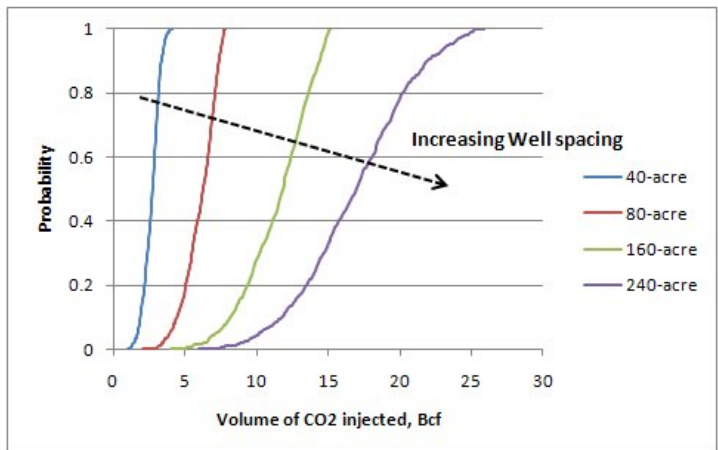

b)

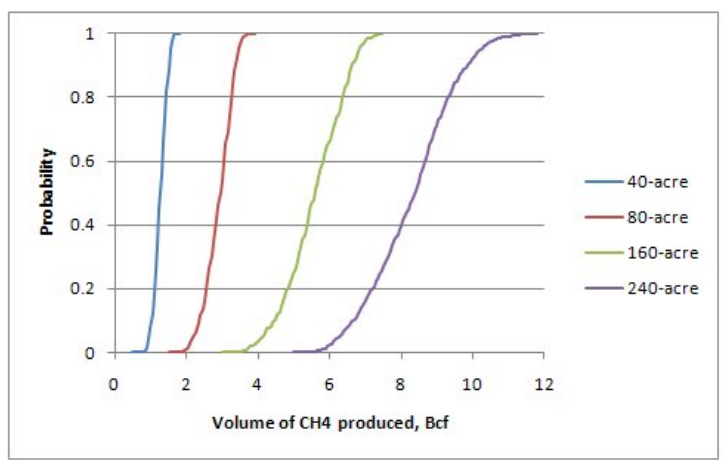

c)

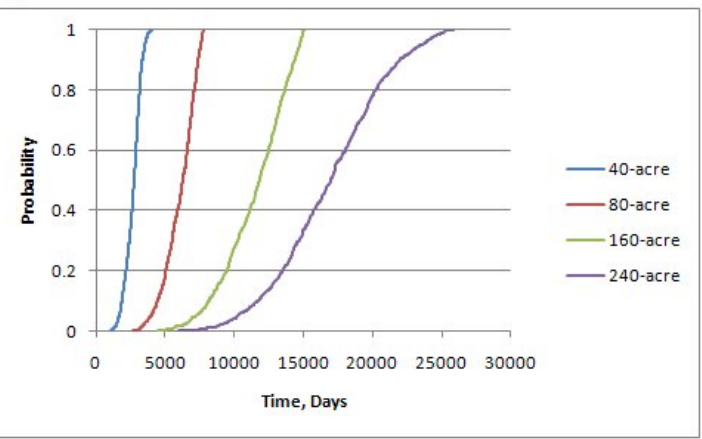

Figure 4.5: Cumulative distribution function graphs for (a) Cumulative $\mathrm{CO} 2$ injection total, (b) Cumulative CH4 production total, (c) Breakthrough time for an inverted 5-spot pattern and constant $\mathrm{CO} 2$ injection rate of $1000 \mathrm{Mscf} / \mathrm{day}$

Figure 4.6 shows the cumulative distribution functions for the volumes of $\mathrm{CO} 2$ sequestered, $\mathrm{CH} 4$ produced and breakthrough times respectively for an inverted 5-spot pattern and 2000 Mscf/day injection rate of $\mathrm{CO} 2$. Mean values of the estimated volumes of $\mathrm{CO} 2$ which can be sequestered in the field of study are 2.9, 5.5, 14.2 and 18.3 Bcf for 40, 80, 160 and 240 - acre well spacing in a 5 spot pattern. Corresponding $\mathrm{CH} 4$ production values are 1.2, 2.3, 5.7 and $7.6 \mathrm{Bcf}$ for a breakthrough time of 1489, 2848, 7315 and 9726 days respectively. 

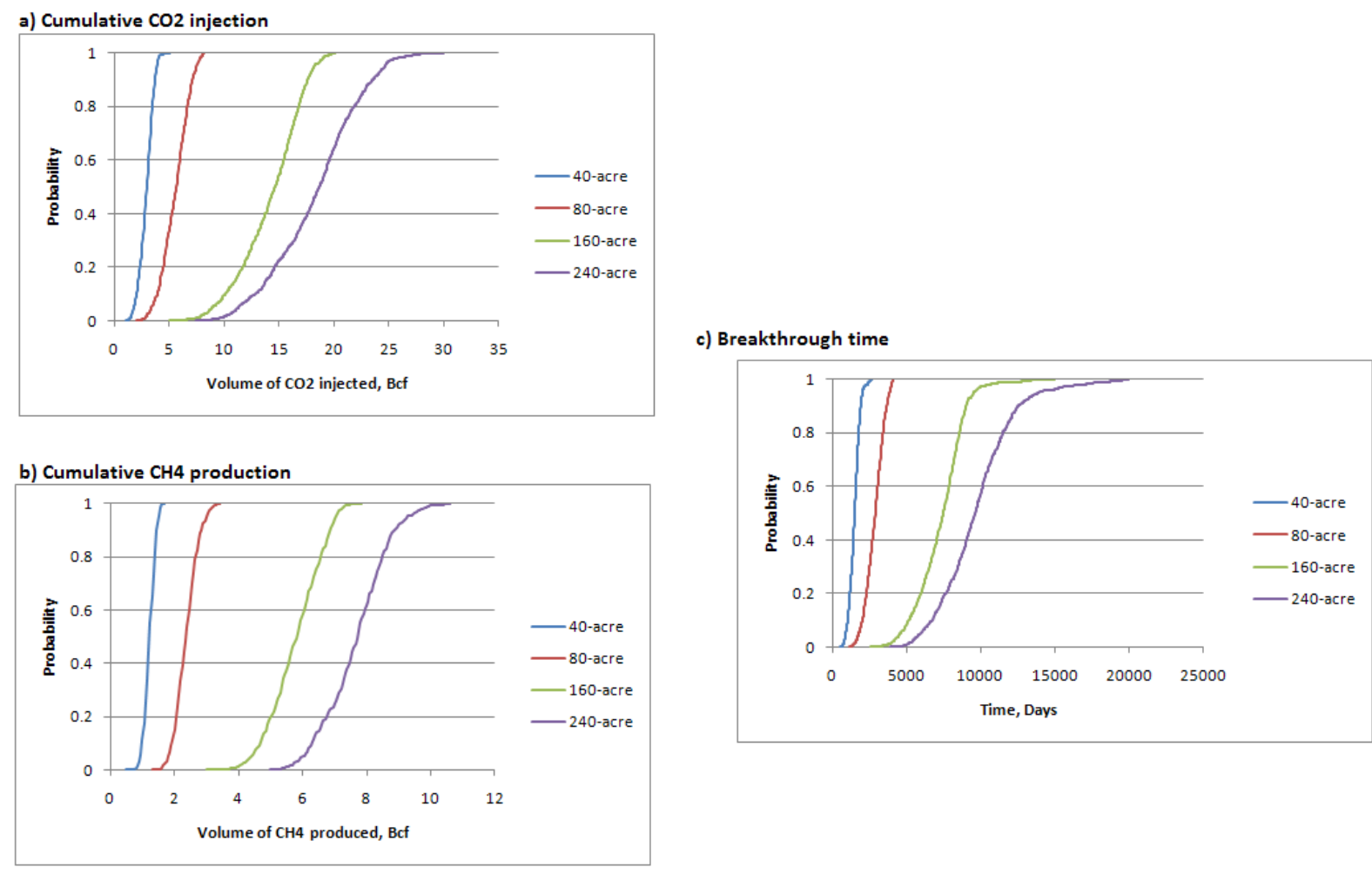

Figure 4.6: Cumulative distribution function graphs for (a) Cumulative CO2 injection total, (b) Cumulative CH4 production total, (c) Breakthrough time for an inverted 5 spot pattern and constant $\mathrm{CO2}$ injection rate of $2000 \mathrm{Mscf} /$ day and varying well spacing

Similarly, figure 4.7 shows the cumulative distribution function graphs of Cumulative $\mathrm{CO} 2$ injection total, Cumulative $\mathrm{CH} 4$ production total and break through time for an inverted 5 spot pattern while CO2 injection was maintained constant at $3000 \mathrm{Mscf} /$ day and the well spacing was varied from 40, 80, 160 and 240 acre. The analysis provided various useful information and the Mean values of the estimated volumes of $\mathrm{CO} 2$ which can be sequestered in the field of study which are 2.7, 6.8, 12.8 and 21.03 $\mathrm{Bcf}$ of $\mathrm{CO} 2$ can be sequestered for 40, 80, 160 and 240 - acre well spacing in a 5 spot pattern. Corresponding $\mathrm{CH} 4$ production values are 1.2, 2.7, 5.2, 8.4 Bcf for a breakthrough time of 1241, 2791, 4867 and 6257 days respectively. 


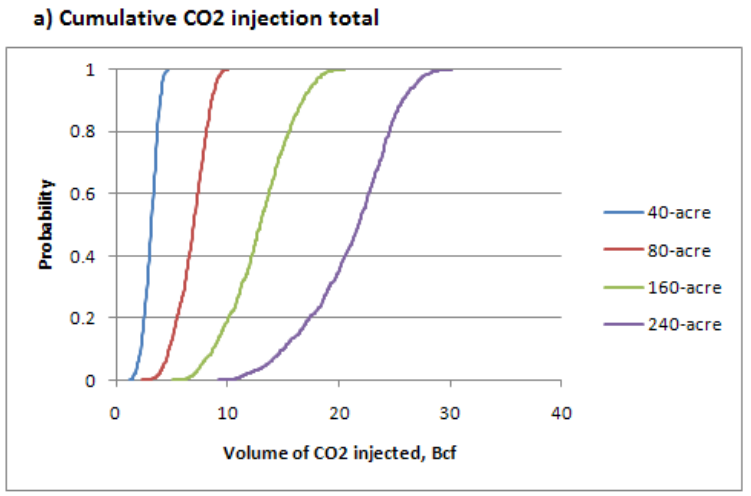

b) Cumulative $\mathrm{CH} 4$ production total

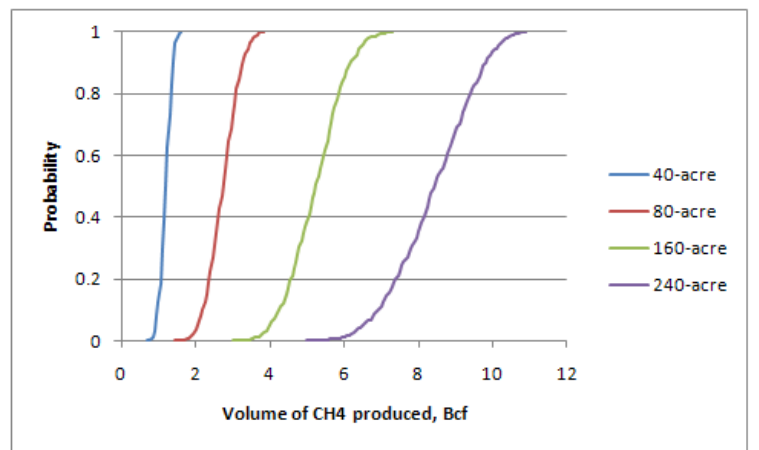

c) Breakthrough time

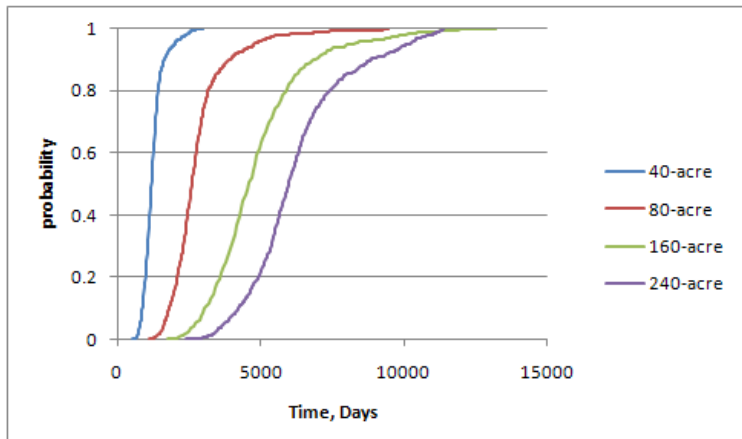

Figure 4.7: Cumulative distribution function graphs for (i) Cumulative $\mathrm{CO} 2$ injection total, (ii) Cumulative CH4 production total, (iii) Breakthrough time for an inverted 5 spot pattern and constant $\mathrm{CO} 2$ injection rate of $3000 \mathrm{Mscf} / \mathrm{day}$ and varying well spacing

The final analysis performed in order to understand the effect of well spacing on the Enhanced coal bed methane recovery and the volume of $\mathrm{CO} 2$ sequestered was with a constant $\mathrm{CO} 2$ injection rate of $4000 \mathrm{Mscf} / \mathrm{day}$ in an inverted 5-spot pattern (Figure 4.8). The various parameters of interest including cumulative $\mathrm{CO} 2$ injection total, cumulative $\mathrm{CH} 4$ production total and the breakthrough time were studied using cumulative distribution graphs. Mean values of the estimated volumes of $\mathrm{CO} 2$ which can be sequestered in the field of study are 2.7, 6.4, 14.4 and 21.0 Bcf for 40, 80, 160 and 240 - acre well spacing in a 5 spot pattern. Corresponding CH4 production values are 1.1, 2.5, 5.6 and 8.4 Bcf for a breakthrough time of 880, 2356, 4879 and 6256 days respectively. 
a) Cumulative $\mathrm{CO} 2$ injection total



b) Cumulative $\mathrm{CH} 4$ production total



c) Breakthrough time

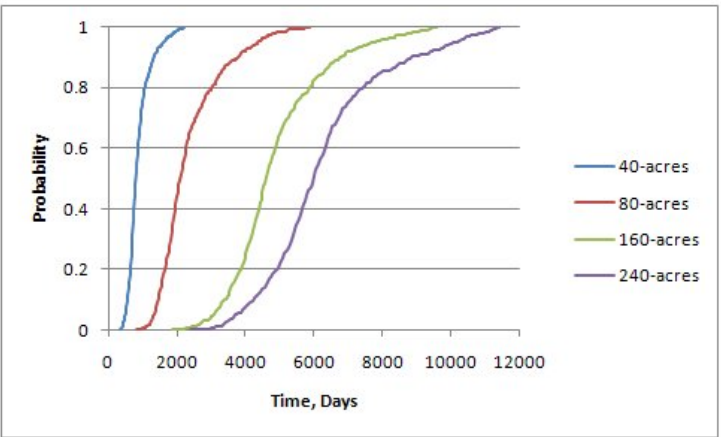

Figure 4.8: Cumulative distribution function graphs for (i) Cumulative $\mathrm{CO} 2$ injection total, (ii) Cumulative $\mathrm{CH} 4$ production total, (iii) Breakthrough time for an inverted 5 spot pattern and constant $\mathrm{CO} 2$ injection rate of $4000 \mathrm{Mscf} / \mathrm{day}$ and varying well spacing.

Based on the four cases conducted above to analyze the effect on well spacing on the cumulative $\mathrm{CO} 2$ sequestration and cumulative $\mathrm{CH} 4$ production, it is evident that all the cases consistently show that, an increase in the well spacing means increase in breakthrough time which thereby indicates increase in $\mathrm{CO} 2$ sequestration total and increase in $\mathrm{CH} 4$ production total.

Fig. 4.9 shows the cumulative distribution functions for the volumes of $\mathrm{CO} 2$ sequestered, $\mathrm{CH} 4$ produced, and water produced normalized to a 40 -acre well spacing basis. For the inverted 5 -spot pattern base case scenario, the mean values of estimated volumes of $\mathrm{CO} 2$ that can be sequestered in Appalachian coals are 2.9, 6.8, 12.8 and 21.03 Bcf Bcf and the CH4 produced is 1.2, 2.7, 5.2, $8.4 \mathrm{Bcf}$ for 40, 80, 160, and 240-acre well spacing, respectively, in a 5-spot injection pattern. Corresponding mean normalized $\mathrm{CO} 2$ injection values are 2.9, 2.77, 3.55 and 3.05 Bcf for 40, 80, 160 and 240-acre well spacing respectively. Normalized mean CH4 production values are $1.22,1.18,1.44$, and $1.27 \mathrm{Bcf}$. Thus, the sensitivity to well spacing of CO2 volumes sequestered and methane volumes produced has normalized to 40 acre well spacing and 
conclusions have been drawn. Based on figure 4.9, which illustrates the $\mathrm{CO} 2$ injection total and Methane production total normalized to 40 acre well spacing, it can be seen that the well spacing does not have significant impact on the $\mathrm{CO} 2$ injection total and Methane production total on an unit area basis.

a) $\mathrm{CO} 2$ injection total- Normalized to 40 acre well spacing

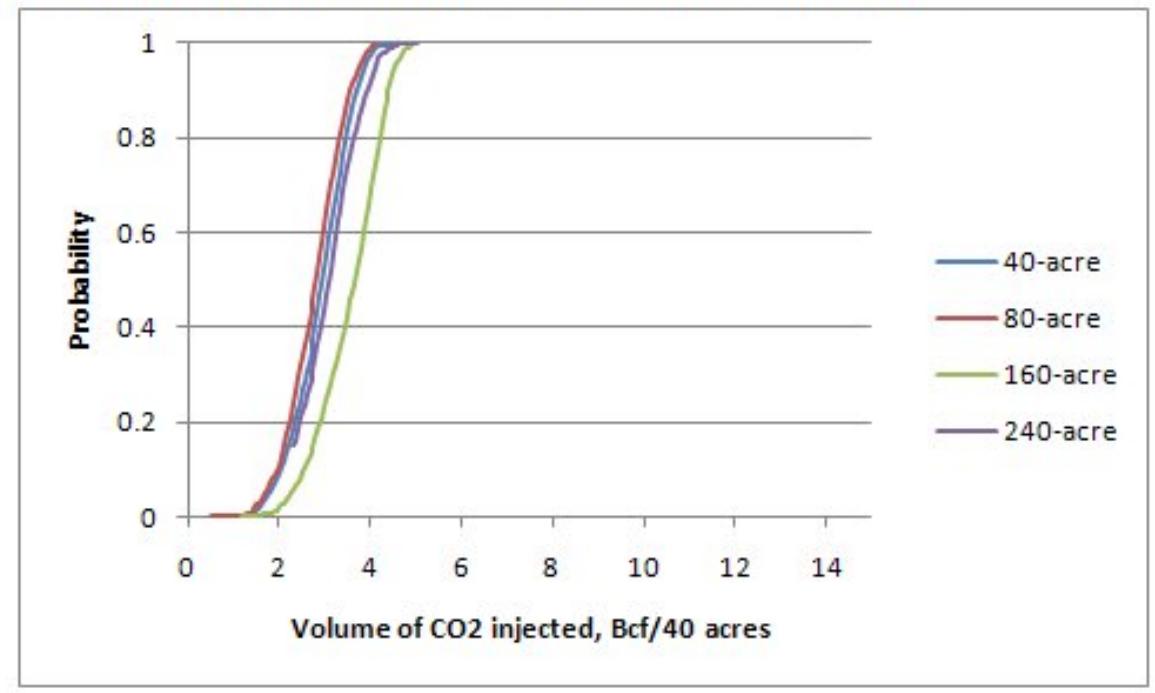

a) $\mathrm{CH} 4$ production total- Normalized to 40 acre well spacing

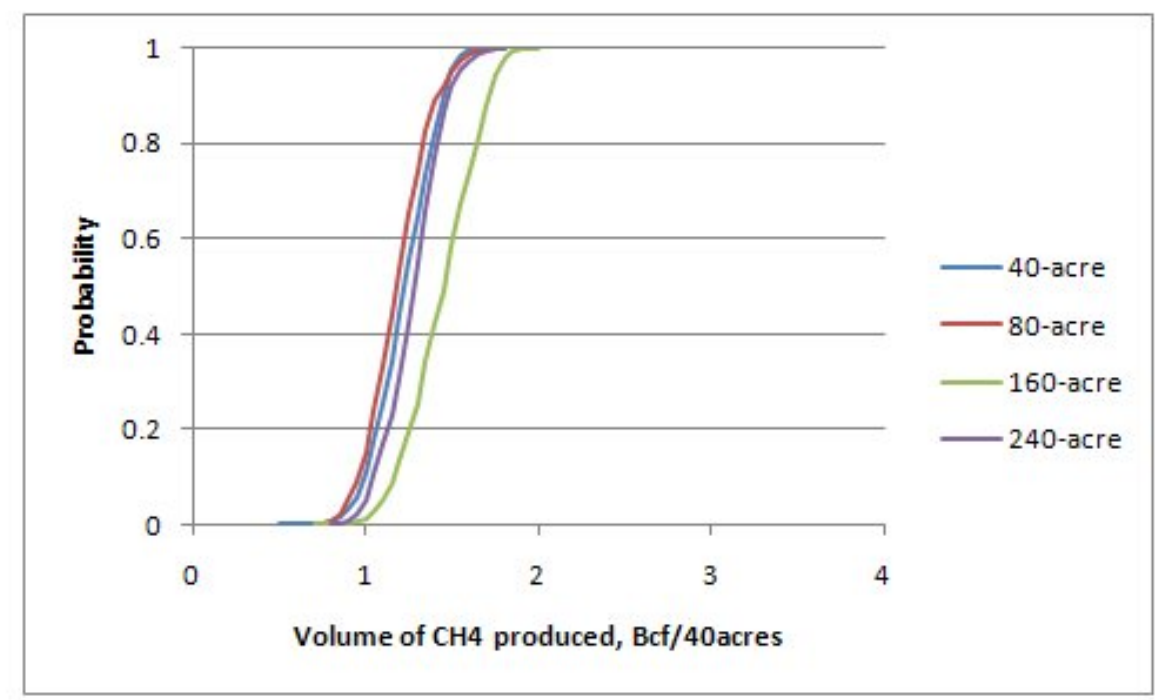

Figure 4.9: Cumulative distribution functions for a) $\mathrm{CO} 2$ injection, b) $\mathrm{CH} 4$ production Inverted 5-spot pattern scenario, for 40, 80, 160, and 240-ac well spacing, normalized to a 40-acre well spacing (80-acre pattern area) basis. 


\subsubsection{Sensitivity study of the Effect of $\mathrm{CO} 2$ injection rate (inverted 5 spot pattern)}

In order to determine the effects of injection rate on the performance of $\mathrm{CO}_{2}$ sequestration and Enhanced $\mathrm{CH}_{4}$ production in the selected field of the central Appalachian Basin, I conducted deterministic simulation modeling studies of $100 \% \mathrm{CO}_{2}$ gas injection for different injection rates of 1000, 2000, 3000 and 4000 Mscf/day on an inverted 5 spot pattern. While the effect of injection rate was studied, the well spacing was maintained constant. Four different cases were studied and in each case the well spacing was maintained constant. The results showing the mean cumulative methane production total and cumulative $\mathrm{CO} 2$ injection total are illustrated in Figures 4.10 and 4.11

Figure 4.10 shows the mean value trends for various different cases of Cumulative $\mathrm{CO} 2$ injection total.

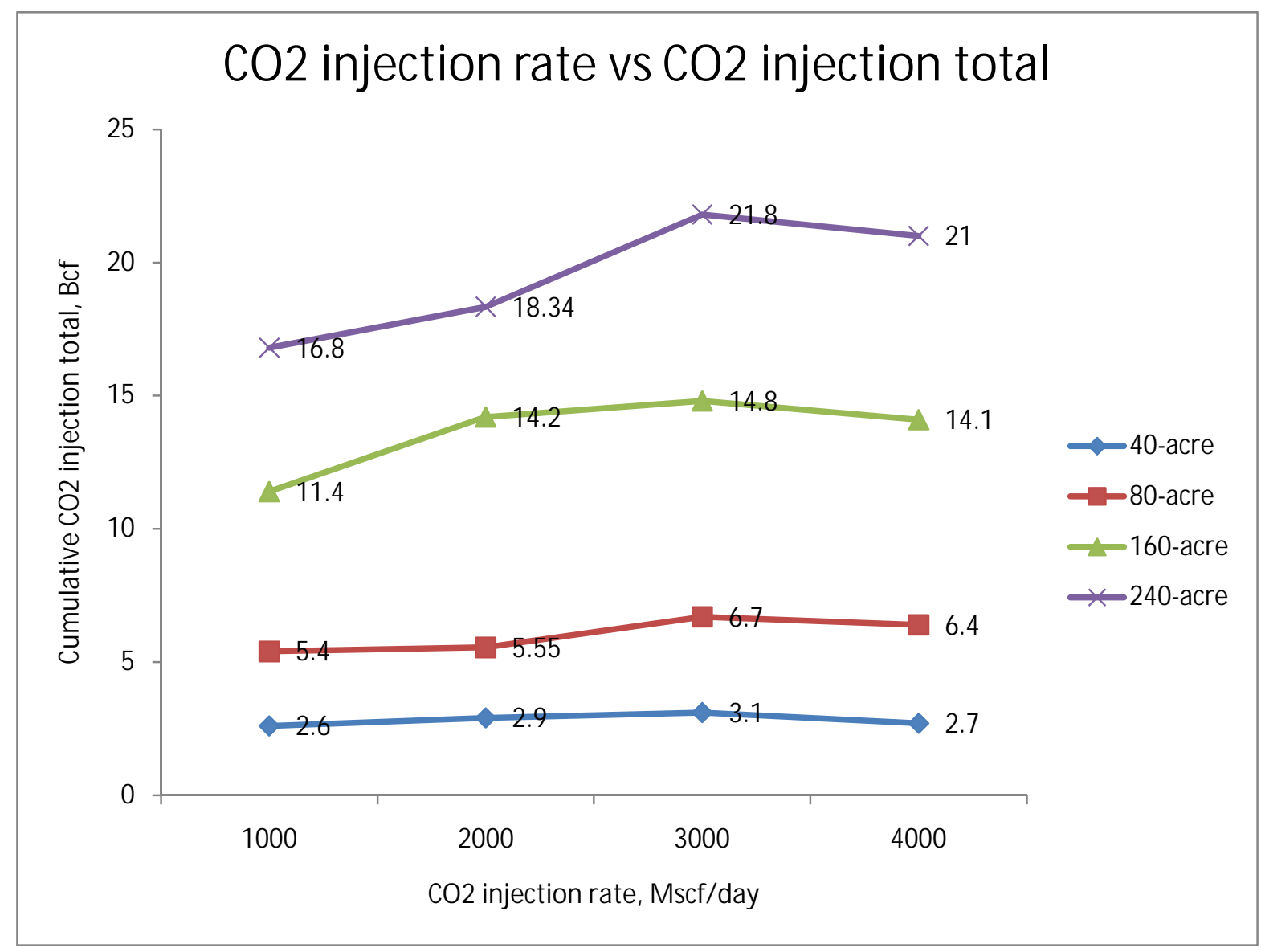

Figure 4.10: Mean values for Cumulative $\mathrm{CO} 2$ injection total at various injection rates. 
On studying figure 4.10, it can be concluded that for all the four cases studied to understand the effect of $\mathrm{CO} 2$ injection rate on the cumulative $\mathrm{CO} 2$ injection total, $3000 \mathrm{Mscf} /$ day shows the best performance and $1000 \mathrm{Mscf} /$ day shows the least favorable performance. The study is further analyzed for Cumulative methane production total to derive a conclusion on the optimum $\mathrm{CO} 2$ injection rate for a balance between $\mathrm{CO} 2$ sequestration and Methane production. Figure 4.11 shows the Mean value trends of Cumulative $\mathrm{CH} 4$ production total as a function of $\mathrm{CO} 2$ injection rate.

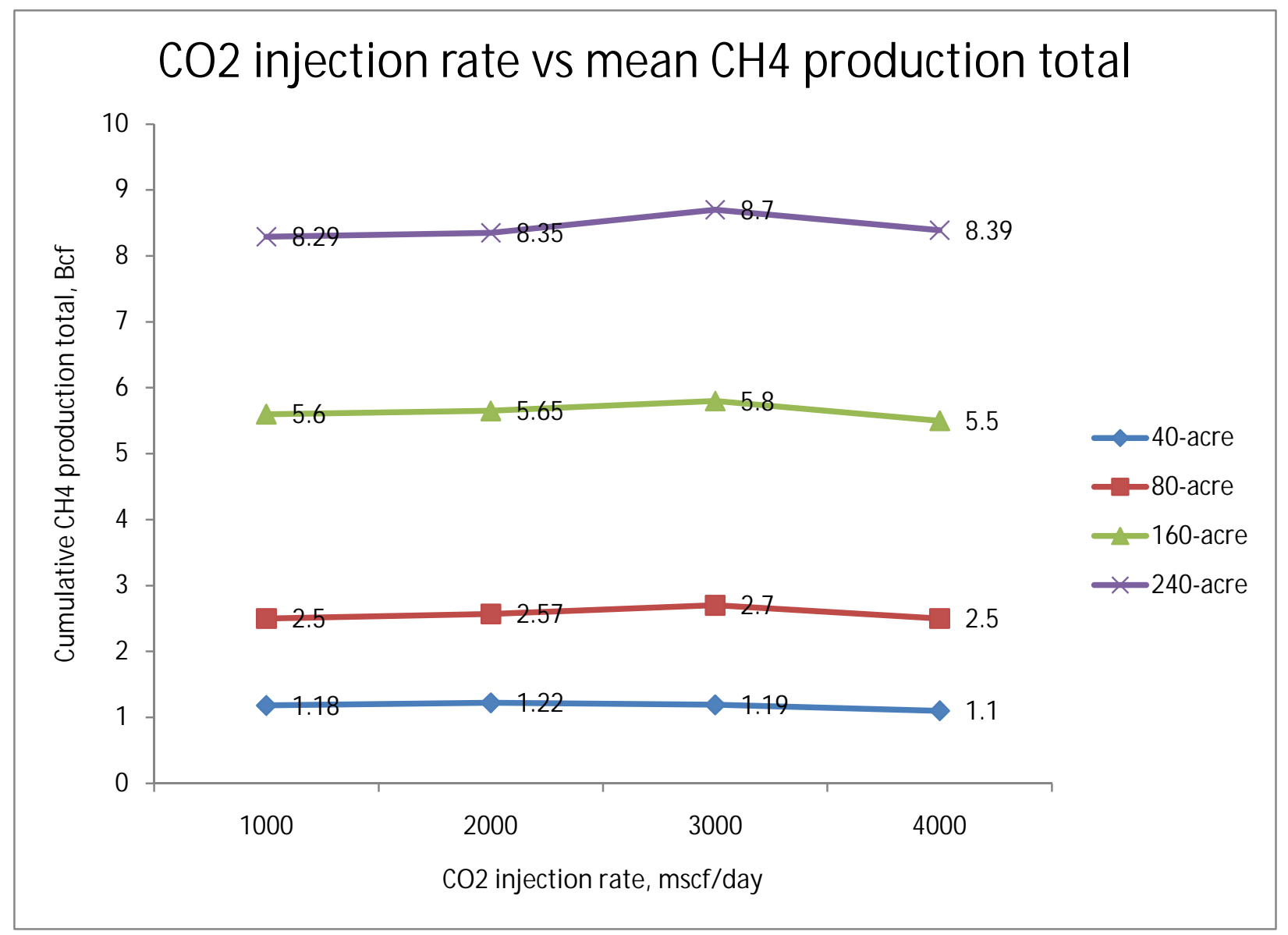

Figure 4.11: Cumulative $\mathrm{CH} 4$ production total as a function of $\mathrm{CO} 2$ injection rate.

From figures 4.10 and 4.11 , it can be concluded that the $\mathrm{CO} 2$ injection rate has effect on the Methane production and $\mathrm{CO} 2$ injection performance. It can be observed in these figures that the mean value trends of both $\mathrm{CO} 2$ injection total and methane production total consistently show that the optimal injection rate is $3000 \mathrm{Mscf} /$ day which produced the maximum methane and injects the maximum $\mathrm{CO} 2$ for all the analyzed cases. Figure 4.12 shows that $\mathrm{CO} 2$ injection rate 
has significant impact on the breakthrough time, thereby reducing the total production and injection time significantly with increase in $\mathrm{CO} 2$ injection rate. Thus, the higher the injection rate, the shorter the project life.

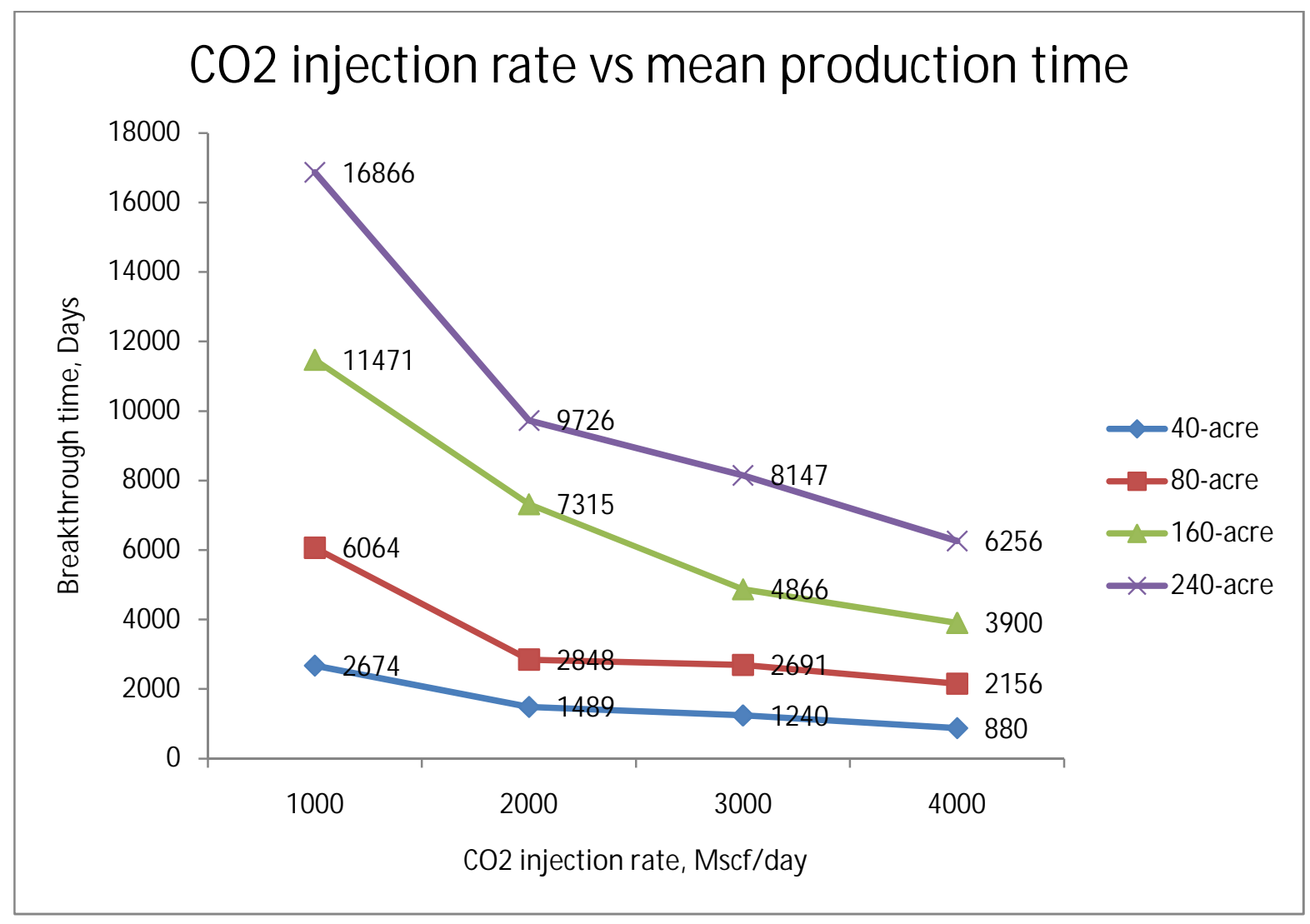

Figure 4.12: Mean production time as a function of $\mathrm{CO} 2$ injection rate.

\subsubsection{Sensitivity analysis of the effect of well pattern}

To study the effect of well pattern on the Cumulative $\mathrm{CO} 2$ injection total and Methane production total, various production profiles were analyzed by keeping all the other operating parameters like $\mathrm{CO} 2$ injection rate, well spacing constant. The effect of two well patterns namely inverted 5-spot pattern and inverted 7-spot pattern were compared. Inverted 5-spot pattern is the most commonly used pattern for Enhance coal bed methane production studies. It was compared with inverted 7-spot pattern which is a hexagonal shaped pattern. Figure 4.13 and 4.14 show 
cumulative distribution function graphs of $\mathrm{CO} 2$ injection total and methane production total for the two patterns.

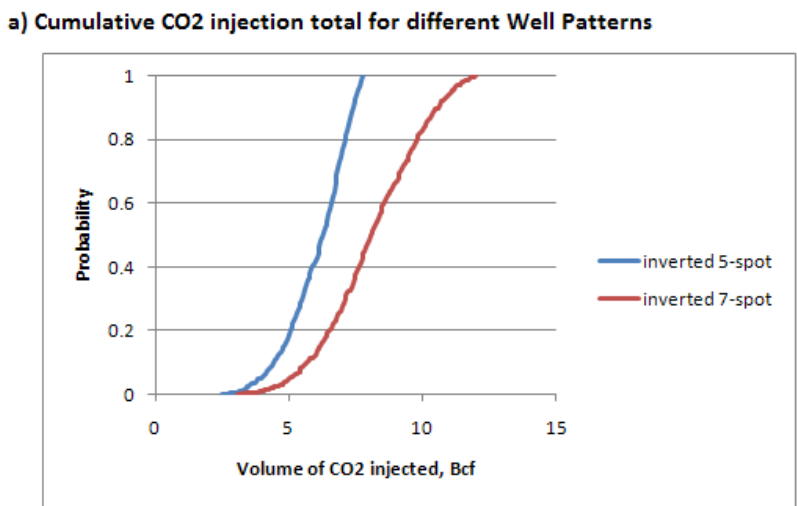

b) Cumulative $\mathrm{CH} 4$ production total for different Well Patterns

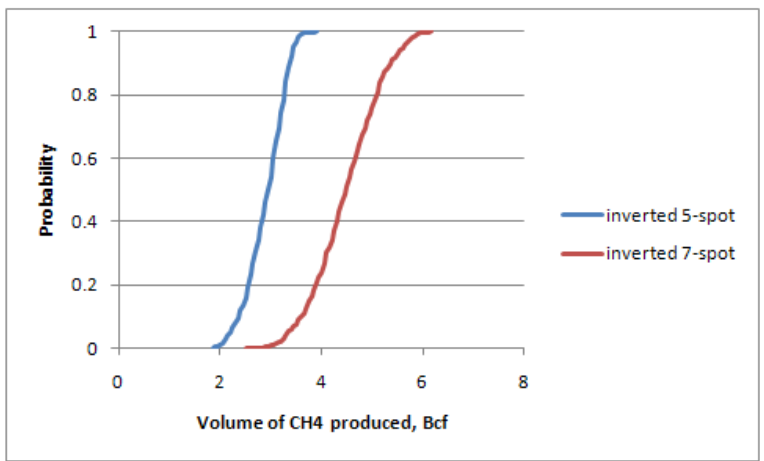

c) Total production time for different well patterns

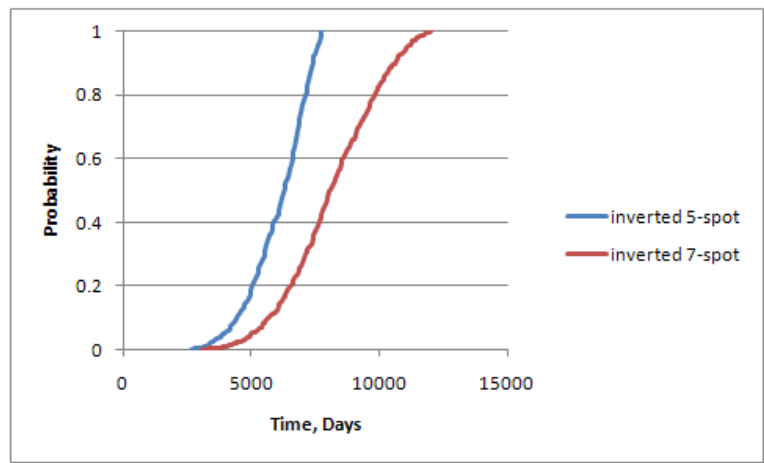

Figure 4.13: Cumulative distribution function graphs for (a) Cumulative $\mathrm{CO} 2$ injection total, (b) Cumulative CH4 production total and c) Breakthrough time for fixed $1000 \mathrm{Mscf} / \mathrm{day} \mathrm{CO} 2$ injection rate and fixed 80 acre well spacing while varying well pattern (inverted 5 spot and inverted 7 spot).

Figure 4.13 shows that for the same area of well spacing and same $\mathrm{CO} 2$ injection rate, an inverted 7-spot pattern can produce more methane and also more $\mathrm{CO} 2$ injection total. This indicates that inverted 7-spot pattern would be more economically feasible. 
a) Cumulative $\mathrm{CO} 2$ injection total for different well patterns

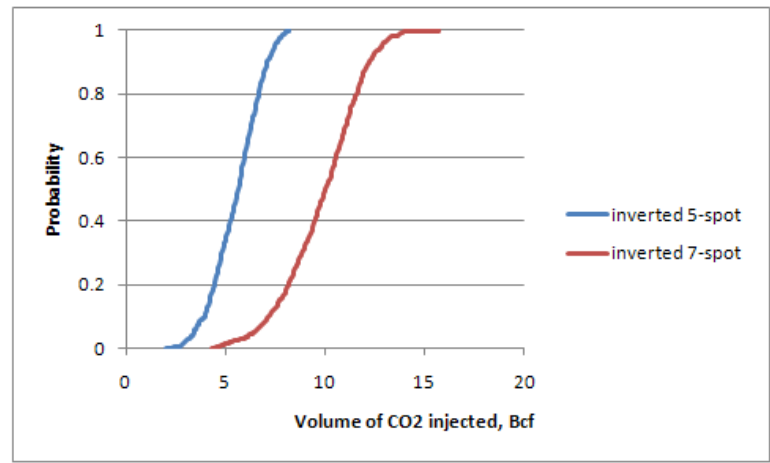

b) Cumulative $\mathrm{CH} 4$ production total for different well patterns

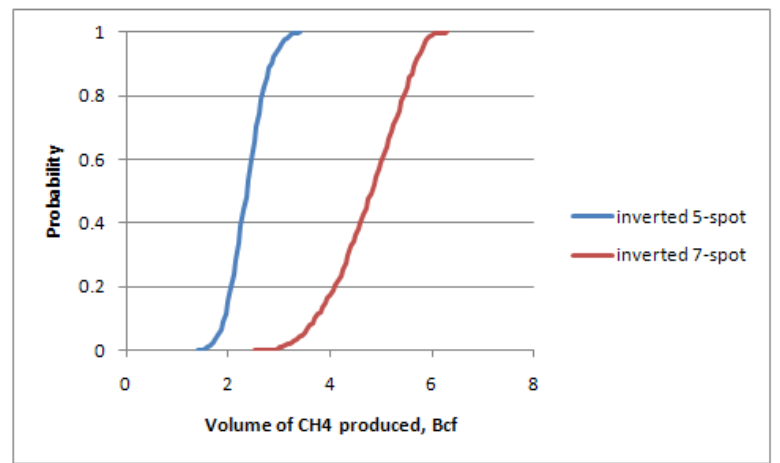

c) Total production time for different well patterns

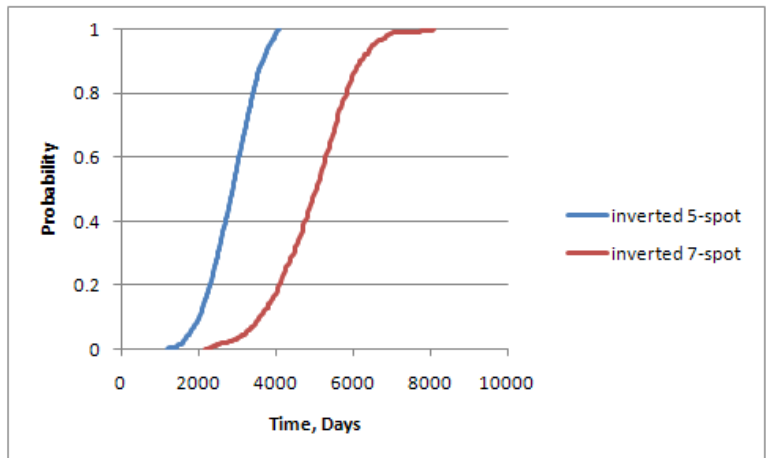

Figure 4.14: Cumulative distribution function graphs for (a) Cumulative $\mathrm{CO} 2$ injection total, (b) Cumulative $\mathrm{CH} 4$ production total, for fixed $2000 \mathrm{Mscf} / \mathrm{day} \mathrm{CO} 2$ injection rate and fixed 80 acre well spacing while varying well pattern (inverted 5 spot and inverted 7 spot).

From figures 4.14, it can be concluded that inverted 7 spot pattern produces more gas and allows the injection of larger volume of $\mathrm{CO} 2$ when compared to inverted 5-spot pattern for the same operating scenarios

To further evaluate the effect of well pattern on the production and injection profiles, the mean values of each of the above cases were analyzed. Figures 4.15 and 4.16 show the mean value trends for inverted 5-spot pattern and inverted 7-spot patterns 


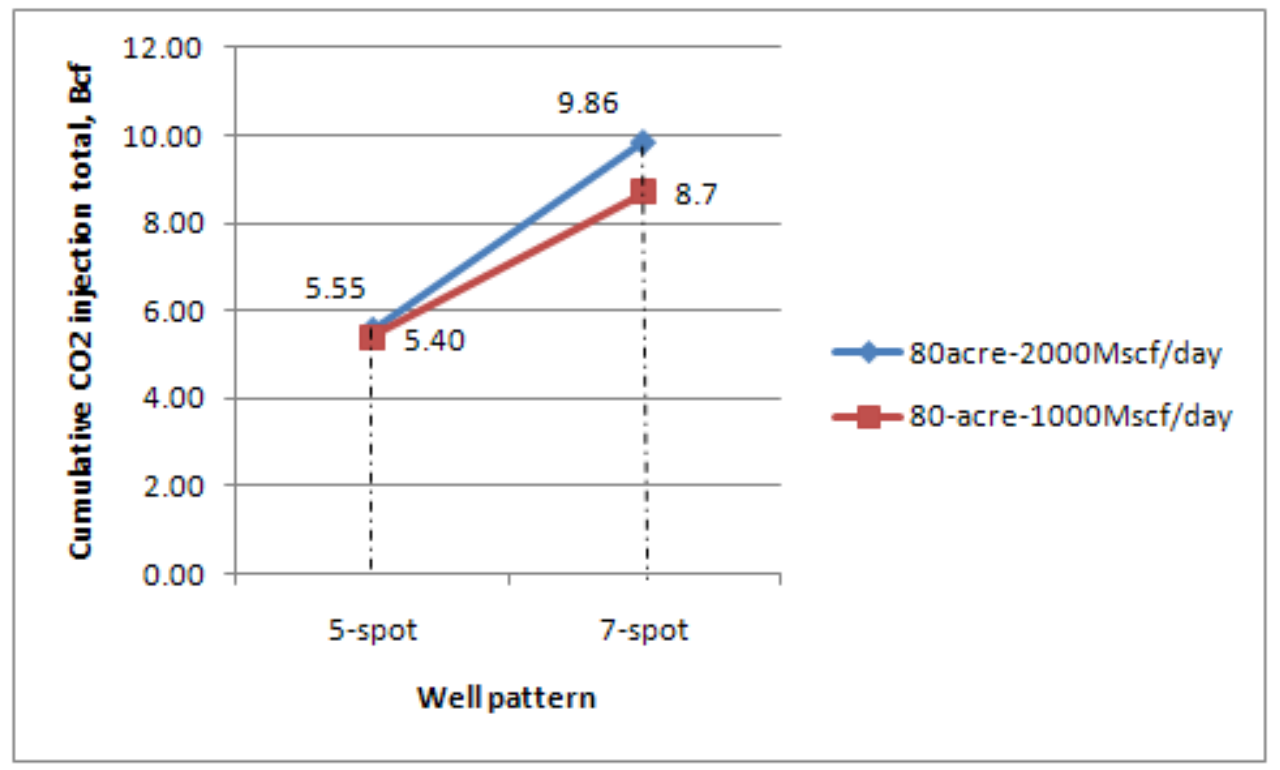

Figure 4.15: The cumulative CO2 injection total for inverted 5-spot and inverted 7-spot pattern while the well spacing and $\mathrm{CO} 2$ injection rates are constant.

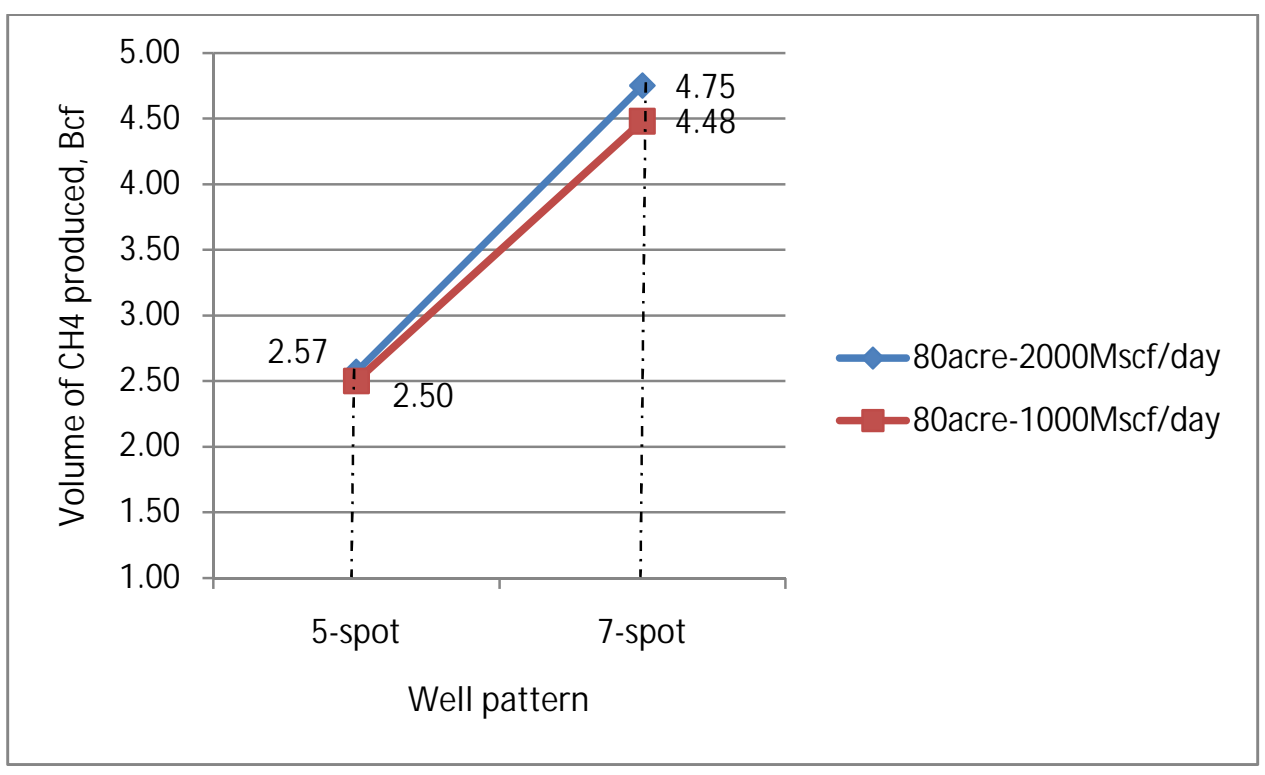

Figure 4.16: Cumulative methane production for inverted 5-spot and inverted 7-spot pattern

Based on figured 4.15 and 4.16, it can be concluded that the well pattern significant effect on cumulative methane production total values and cumulative $\mathrm{CO} 2$ injection total values. From the two different cases analyzed to study the impact of well pattern on the $\mathrm{CO} 2$ injection total and methane production total, it can be concluded that inverted 7 spot pattern is better than inverted 5-spot pattern in terms of cumulative methane production and $\mathrm{CO} 2$ sequestration. Finally, various production profiles namely methane production total and methane production 
rate was analysis for a single case of inverted 5- spot and inverted 7-spot pattern. They are illustrated in figures 4.17 and 4.18 .

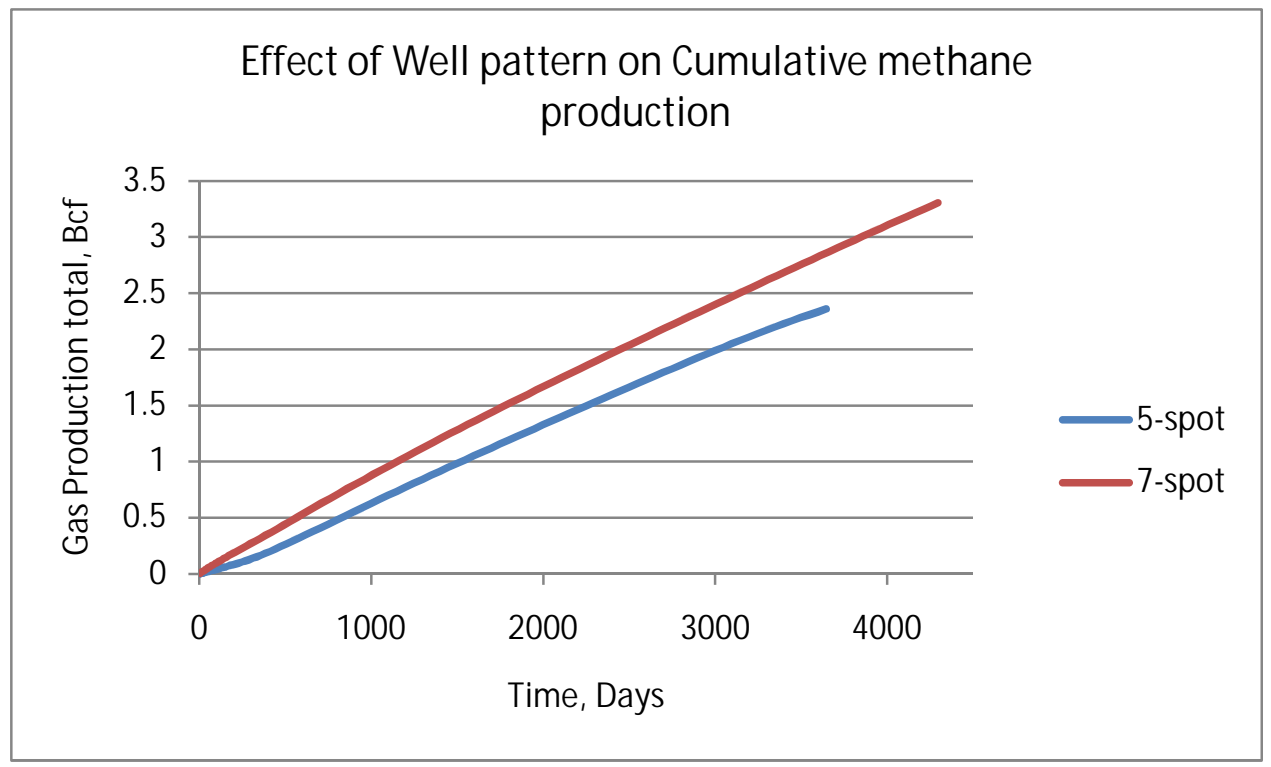

Figure 4.17: Cumulative methane production total for inverted 5-spot and inverted 7-spot patterns

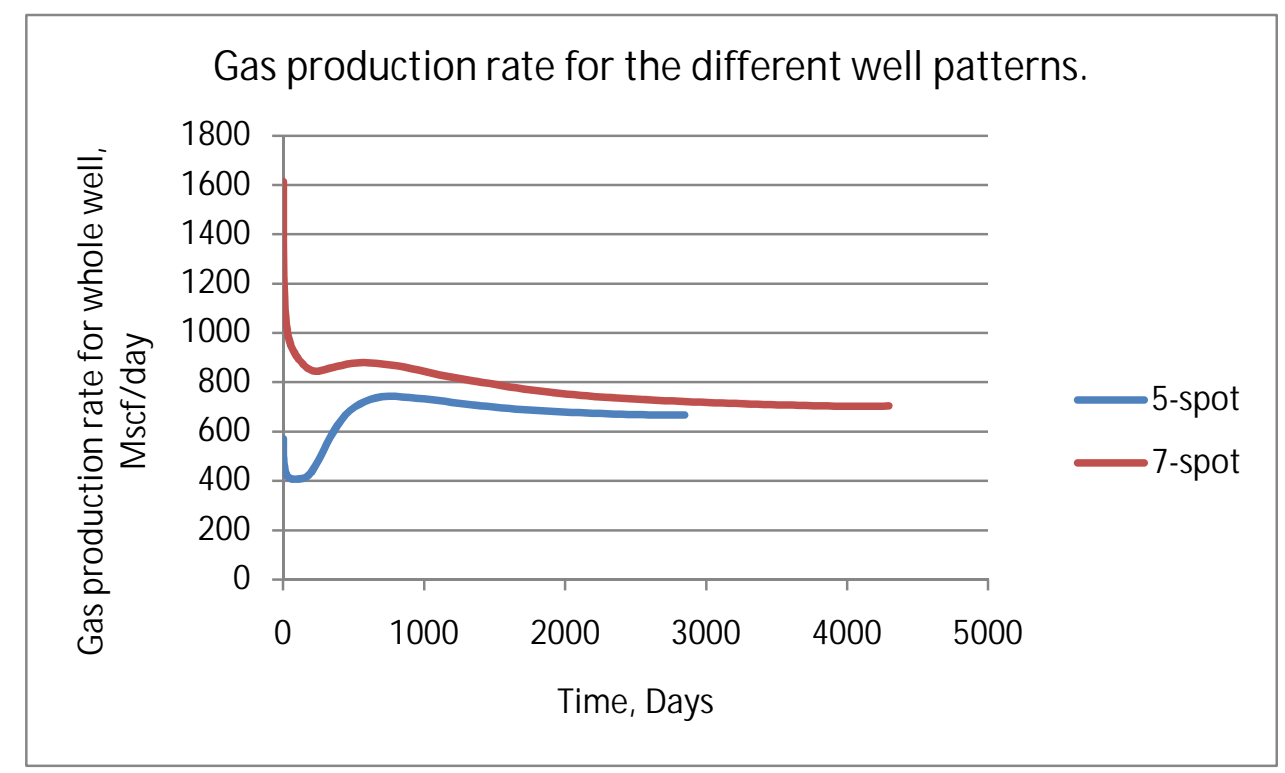

Figure 4.18: Methane production rate for inverted 5-spot and inverted 7-spot patterns 


\section{CHAPTER 5}

\section{CONCLUSION AND RECOMMENDATION}

\subsection{CONCLUSIONS}

- Methane resources and CO2 sequestration potential in the Seam Pocahontas No.3 of the Central Appalachian Basin coals is abundant. Injection of $100 \% \mathrm{CO} 2$ in coal seams using an inverted 5-spot pattern and inverted 7-spot pattern with average net thickness of $30 \mathrm{ft}$ results in average volumes of $\mathrm{CO} 2$ sequestered between 5.5 and $9.8 \mathrm{Bcf}$ and average volumes of methane produced between 2.3 and $4.7 \mathrm{Bcf}$ on an 80 -acre per well.

- Various well spacing including 40 acre, 80 acre, 160 acre and 240 acre per well were studies to understand its impact on the Cumulative $\mathrm{CO} 2$ injection and Methane production total. Well spacing sensitivity studies for $100 \% \mathrm{CO} 2$ injection indicate that total volumes of $\mathrm{CO} 2$ sequestered and methane produced on a unit-area basis do not change significantly with spacing up to 240 acres per well. There is however, impact on the breakthrough time. The mean breakthrough time for a $2000 \mathrm{Mscf} / \mathrm{day} \mathrm{CO} 2$ injection rate case is 1489 days, 2848 days, 7315 days, 9726 days for 40 acre, 80 acre, 160 acre and 240 acre respectively.

- Gas injection rates show effect on the methane production and $\mathrm{CO} 2$ injection total. Of the various injection rates used in the study, it was found that on an overall, $3000 \mathrm{Mscf} / \mathrm{day}$ is an optimal injection rate in terms of Methane production and $\mathrm{CO} 2$ injection total.

- Well patterns of inverted 5-spot and inverted 7-spot were studied during this research. The results indicate that the inverted 7-spot pattern produces significantly large amount of Methane when compared to inverted 5-spot pattern on a pattern basis. 


\subsection{RECOMMENDATIONS}

- An economic model should be designed to further evaluate the effect of well pattern on the methane production and $\mathrm{CO} 2$ injection balance.

- Certain issues involved with injecting Carbon dioxide into coal bed reservoirs like coal swelling were not taken into account in this study. Further studies are recommended for the better understanding of these issues. 


\section{REFERENCES}

1. Bromhal, G.S. "Simulation of $\mathrm{CO} 2$ sequestration in Coal Beds: The effects of Sorption Isotherms." Chemical Geology (Chemical Geology), 2005: 217.

2. C.Milici, Robert. Assessment of Appalachian Basin Oil and Gas resources: carboniferous Coal-Bed Gas Total Petroleum System. U.S Geological Survey.

3. Creties D.Jenkins, DeGolyer and MacNaughton, Charles M.Boyer. "Coalbed and Shale Gas Reservoirs." Distinguished Author series, 2008.

4. D.H.S. Law, Van der Meer, L.G.H, W.D.Gunture. "Numerical Simulator Comparison Study for Enhanced Coalbed methane recovery processes PartI: Pure Carbon Dioxide Injection." SPE 75669, 2002.

5. D.J.Remner, T.Ertrekin, G.R.King. "A parametric study of the Effects of coal seam properties on Gas drainage Efficiency." SPE paper 13366, 1984.

6. David H.-S. Law, SPE, Alberta Research Council (ARC) Inc., L.G.H. (Bert) van der Meer, SPE, TNO-NITG and W.D. (Bill). "Numerical Simulator Comparison Study for Enhanced Coalbed Methane Recovery." SPE 75669.

7. E.A.Rehbein, C.D.Henderson and R.Mullennex. No.3 Pocahontas coal in southern West Virginia-Resources and depositional trends. West Virginia geological and Economic Survey Bulletin, 1981.

8. EmissionCredits. 2009. http://www.emissioncreditscanada.com.

9. Energy, U.S Department of. 2004.

10. G.H Wood, T.M Kehn, M.D. Carter and W.C Culbertson. "Coal resource classification system of the U.S. Geological Survey." U.S.Geological survery circular 891, 1983.

11. H.J.M. Pagnier, F.Van Bergen, E.Kreft, L.G.H van der Meer and H.J simmelink. Field Experiment of ECBM-CO2 in the Upper Silesian Basin of Poland (RECOPOL). SPE 94079, 2005.

12. I.Palmer, J. Mansoori. "How permeability depends on stress and pore pressure in Coalbeds: A new model." SPEREE, December 1998: 539.

13. J.R.Kelafant, C.M.Boyer and M.D.Zuber. "Production Potential and Strategies for Coalbed methane in the Central Appalachian Basin." SPE 18550, 1988.

14. K.J.Englund, J.F.Windolph, R.E.Thomas. Origin of thick low surfur coal in the Lower Pennsylvanian Pocahontas Formation, Virginia and West Virginia, in Lyons, P.C and Rice, C.L., eds.,Paleoenvironmental and tectonic controls in coal-forming basis of United States: Geological society of America special paper, 1986. 
15. L.D.Harris, and R.C.Milici. Characteristics of thin skinned style of deformation in the Southern Appalachians and potential hydrocarbon traps. U.S Geological survey professional paper, 1977.

16. Mathew J.Mavor, John R.Robinson, John Gale. "Testing for CO2 sequestration and Enhanced methane production from coal." SPE 75683, 2002.

17. McColloch, G.H. West Virginia, in Keystone Coal Industry Manual. Intertec Publishing company, 1995.

18. Olufemi Odusote, Bromhal. "Carbon dioxide sequestration in coal seams: A parametric study and development of a practical prediction/Screening tool using Neuro simulation." SPE 90055, 2004.

19. Olufemi Odusote, Duane H.Smith, W.Neal Sams, Grant Bromhal, Sinisha Jikich. "Simulating Carbon dioxide sequestration/ECBM production in coal seams: Effects of permeability anisotrophies and other coal properties." SPE 84423, 2003.

20. Reinaldo J. Gonzalez, Aiysha Sultana, Anne Y. Oudinot, Scott R. Reeves. "Incorporating Geostatistical Methods with Monte Carlo." International coal bed methane symposium, 2006.

21. S.D.Mohaghegh, U.N. Nunsavathu, J.Jalal, M.Tovar, N.maricic, R.Gaskari and S.Ameri. "Development of a series of National Coal bed Methane Databases." SPE 98011, 2005.

22. S.R.Reeves. "Enhanced CBM recovery, Coalbed CO2 sequestration Assessed." Oil and Gas Journal, July 2003: 49.

23. Scott Reeves, Anne Oudinot, Advanced Resources International, Inc. "The Allison Unit CO2-ECBM Pilot - A Reservoir and Economic Analysis." 2002.

24. Sinisha A Jikich, Grant S.Bromhal, F.Burcu Gorucu, Turgay Ertekin, Duane H.Smith. "Economics of Enhanced Coalbed methane (ECBM) and CO2 sequestration with Horizontal wells." SPE 91391 (SPE 91391), 2004.

25. Sinisha A.Jikich, Duane H.Smith, W.Neal Sams, Grant S.Bromhal. "Enhanced Gas Recovery(EGR) with Carbon Dioxide Sequestration: A simulation study of Effects of injection strategy and Operational Parameters." SPE 84813, 2003.

26. W.R.Hibbard. Virginia coal, an abridged history:. Virginia center for Coal and Energy Research, 1990.

27. X.R.Wei, G.X.Wang, P.massarotto and S.D Golding. "A case study on the Numerical Simulation of Enhanced Coalbed Methane Recovery." SPE 101135, 2006.

28. Yee.D, Puri.R and. "Enhanced Coal Bed methane Recovery." SPE 20732, 1990. 